\title{
Aggregate Nominal Wage Adjustments: New Evidence from Administrative Payroll Data*
}

\author{
John Grigsby
}

Ahu Yildirmaz

February 2, 2019

\begin{abstract}
Using administrative payroll data from the largest U.S. payroll processing company, we document a series of new facts about nominal wage adjustments in the United States. We first show that per-period contract ("base") wages are a large share of compensation and are more persistent than bonuses suggesting that base wages may be a better proxy for allocative wages than average hourly earnings. Nominal base wage declines are much rarer than previously thought with only $2 \%$ of job-stayers receiving a nominal base wage cut during a given year. However, accounting for shifts in nominal wages of job-changers implies that aggregate nominal wages are more flexible than the base nominal wages of job-stayers. Other forms of compensation, such as bonuses, work similarly to sales in the output price literature, and provide a margin of short-run adjustment which may be important for earnings dynamics and for financially constrained firms. In addition, nominal wage adjustments are state-dependent: downward aggregate nominal wage adjustments were much more common during the Great Recessions than in the subsequent recovery period, and these downward adjustments were concentrated in industries hit hardest by the recession and in shrinking firms. Finally, we provide evidence that the flexibility of new hire base wages is similar to that of existing workers. Collectively, our results can be used to discipline models of worker nominal wage adjustments and models of wage rigidity.
\end{abstract}

*We thank Mark Aguiar, Susanto Basu, Steve Davis, Fatih Guvenen, John Haltiwanger, Jonathan Hazell, Pete Klenow, Alan Krueger, Marianna Kudlyak, Andre Kurmann, Alex Mas, Ben Schoefer, John Shea, Rob Shimer, Gary Solon and Joe Vavra as well as seminar participants at the 2018 American Economic Association meetings, Chicago, the European Central Bank, Maryland, Michigan, Minnesota, Princeton, the San Francisco Federal Reserve, USC, and Wharton for helpful comments. Per our use agreement, ADP approved the paper topic ex-ante. Additionally, ADP reviewed the paper prior to disribution with the sole focus of making sure that the paper did not release information that would compromise the privacy of their clients or would reveal proprietary information about the ADP business model. Authors' contact information: jgrigsby@uchicago.edu, erik.hurst@chicagobooth.edu. and Ahu.Yildirmaz@ADP.com. 


\section{Introduction}

Nominal rigidities are an important component of many models of aggregate fluctuations. A large literature has developed using micro data to establish a key set of moments of output price adjustment, which have proven very influential for theories to discipline the nature of nominal price rigidities. ${ }^{1}$ However, the literature using micro data to document nominal wage adjustment is far less extensive. As a result, the nature of nominal wage stickiness remains a central question within both the macroeconomics and labor economics literatures. For example, at the 2014 Jackson Hole Symposium, Janet Yellen speculated that downward nominal wage rigidity was an important contributor both to why wages did not fall more during the Great Recession and why they did not increase at a faster rate during the subsequent recovery.

There are three reasons why the literature using micro data to measure nominal wage adjustment has remained underdeveloped. First, and most importantly, existing data sets are not well-suited to measure the extent of nominal wage rigidities. Household surveys often define the nominal wage by dividing self-reported earnings by self-reported hours. Any measurement error in either earnings, hours worked, or even self-reported hourly wages can result in a substantial upward bias in the volatility of individual level wage changes. Administrative datasets, on the other hand, have high quality panel data on quarterly or annual earnings but usually lack the measures of individual hours worked necessary to construct a wage. $^{2}$

Second, the composition of compensation varies across workers and over time. For example, worker compensation includes their guaranteed contract earnings as well as commissions, tips, bonuses, performance pay, overtime premiums, and employer-provided fringe benefits. Existing household and administrative datasets do not decompose the different types of compensation into their components nor do they include measures of employer-provided fringe benefits. In many theories of employment dynamics, the present value of earnings determine fluctuations. To the extent that different forms of compensation adjust differently, there are gains to understanding adjustment patterns of each form of compensation separately, as more persistent forms of compensation may be a better proxy for the permanent wages of

\footnotetext{
${ }^{1}$ See, for example, Bils and Klenow (2004), Klenow and Kryvtsov (2008), and Nakamura and Steinsson (2008) for important contributions.

${ }^{2}$ There are some exceptions. Barattieri et al. (2014) attempts to correct for measurement error in selfreported hourly wages among SIPP respondents when examining nominal wage adjustments. Kurmann and McEntarfer (2018) and Jardim et al. (2019) use administrative data from Washington state which records measures of both earnings and hours to explore changes in earnings-per hour. Throughout the paper, we will discuss how having administrative data on actual worker wages contrasts with the results of these papers and other papers in the literature.
} 
some models.

Finally, different models employ different notions of nominal wage rigidities. Many models of frictional labor markets require separate measures of nominal wage adjustments for those who remain with the same employer and for those who switch employers. In many of these models, it is the flexibility of new hire wages that is important for aggregate employment fluctuations. However, most New Keynesian models do not make a distinction between job-stayers and job-changers and instead require measures of aggregate nominal wage adjustments including both margins of adjustment. For example, in order to match aggregate employment and wage dynamics during and after the Great Recession, one would need measures of nominal wage changes inclusive of those who remain on the job and those who switch jobs. This variety of wage rigidity notions puts further requirements on data seeking to understand nominal adjustments.

In this paper, we use administrative data from ADP, LLC (henceforth known as ADP) - one of the world's largest payroll processing companies - to produce a series of new facts about aggregate nominal wage adjustment in the U.S. over the last decade. Our data is unique in that it: (1) includes administrative anonymized records of workers' per-period nominal wage, (2) has a sample of about 20 million workers per month which are generally representative of the US population, (3) provides data for the universe of workers within a firm, (4) allows workers to be tracked both within and across firms over time, (5) includes administrative records on various other forms of compensation including bonuses and fringe benefits, and (6) spans multiple years so as to examine business cycle variation. The data allow us to compute measures of nominal wage adjustments separately for job-stayers and job-changers, as well as construct a composite aggregate measure including both stayers and changers. Additionally, we create measures of nominal wage adjustments both with and without bonuses and employer-provided fringe benefits. Finally, we explore the cyclicality of new hire wages. Collectively, our results paint a relatively complete picture of nominal wage adjustments for workers and firms in the U.S. during from 2008 to 2016.

We first describe the composition of compensation. For most workers, annual "base earnings" comprise essentially all annual earnings (excluding employer-provided fringe benefits). For a worker who is paid hourly, this is their base hourly wage times the number of hours they worked. For a salaried worker, this is simply their annual contracted salary. However, for some workers, bonuses, commissions, performance pay and overtime premiums are also important. For about ten percent of workers, non-base pay accounts for $20 \%$ of annual earnings. We document that the share of earnings accruing from bonuses is monotonically increasing in the individual's base wages. For individuals in the bottom forty percentiles of the base wage distribution, hardly any of their annual earnings comes from bonus pay. 
However, for the median household, the 80th percentile, the 95th percentile and the 99th percentile of the base wage distribution, bonuses account for about 3 percent, 5 percent, 10 percent and 16 percent of their annual earnings, respectively.

We also measure a worker's total annual compensation inclusive of employer-provided health and retirement fringe benefits. The share of annual fringe benefits out of total annual compensation is hump-shaped in individual base wages. For households between the 0 and 20th percentile of the base wage distribution, the fringe benefit share rises from about 5 percent to 12 percent. The fringe benefit share is relatively constant at about 12 percent between the 20th and 90th percentile of the worker wage distribution and then declines to about 8 percent for the top percentile.

Thus, in order to measure adjustments in a worker's total nominal wages, one must consider wages accruing from base earnings, bonuses, and fringe benefits. The second part of the paper measures how these various components of nominal wages adjust. Like most of the literature, we begin by focusing on a measure of nominal wages excluding bonuses, fringe benefits and other irregular forms of compensation for a sample of workers who remain continuously employed with the same firm. We refer to this sample as our "job-stayer" sample. We measure a worker's "base wage" as either their hourly wage (for workers paid hourly) or their per pay-period contracted compensation (for salaried workers). A worker's per payperiod contracted compensation is their contractually obligated annual salary divided by the annual number of pay-periods during the year: that is, their contractually obligated weekly, bi-weekly or monthly earnings. We discuss that a key input into many macro models of labor market fluctuations is the extent to which base wages evolve.

Our first main result is that nominal base wage cuts are exceedingly rare. During our entire sample period, only about $2.5 \%$ of all workers received a nominal base wage cut during a year. The number was slightly higher for salaried workers compared to workers paid hourly (3.6\% vs. 1.8\%). On average, about one-third of both hourly and salaried workers who remain on the job received no nominal wage adjustment during a given year. Therefore, about two-thirds of both hourly and salaried workers receive a positive nominal base wage increase during a given year. We also document a missing mass of small positive changes with many more workers receiving a nominal base wage increase of 2 to 4 percent than from 0.1 to 2 percent. The patterns are similar regardless of whether or not the worker receives an annual bonus, whether or not the worker receives frequent commission/tips, and whether or not the worker's hours fluctuate substantively during a given year. Our results imply a duration of nominal base wages for the typical worker who remains continuously employed on the same job of about 6 quarters.

We next turn to the measurement of base wage adjustments for the aggregate economy 
including data on both job-stayers and job-changers. Almost all workers that transition across jobs experience a nominal base wage change. Indeed, $38 \%$ of job-changers experience a decline in their nominal base wage. Given that job-switchers are a non-trivial share of the economy, we create a broader measure of nominal base wage flexibility pooling together both job-stayers and job-changers. Doing so, we find that roughly 24 percent of all workers experience a base wage change during a given quarter and 71 percent experience a base wage change during a given year. Including both the job-stayers and job-changers, 8.5 percent of workers experience a nominal base wage decline with essentially all of the declines being driven by job-changers.

That the aggregate economy, including job-switchers, exhibits a substantially higher degree of base wage flexibility than the sample of job-stayers is another key insight of this paper. Models seeking to understand the muted fluctuations in mean nominal wages over the cycle must reckon with this finding that aggregate wages are made more flexible on the downside by the presence of job-changers. In addition, models without realistic job search components should be cautious about using wage rigidity estimates from job-stayer samples, as is standard in the literature, for doing so will result in overstating the degree of rigidity in the economy as a whole. Including both job-stayers and job-changers and accounting for other forms of compensation yields an average duration of nominal wages (inclusive of base wages and bonuses) of about 5.5 quarters. However, there is still an asymmetry in adjustment with nominal wage increases being seven times more likely than nominal wage cuts.

we need to rewrite these next few paragraphs on bonuses....

We next turn to assessing how bonuses evolve for job-stayers. Unlike base wage changes which are very persistent, bonuses are essentially transitory. Given that, bonuses only have a small effect on the user cost of hiring a worker. In that sense, bonuses are akin to sales in the pricing literature. However, for some applications, understanding the evolution of wages inclusive of bonuses may be more appropriate than understanding the evolution of base wages.

We document that annual bonuses vary substantively from year to year. As a result, accounting for bonuses, 16 percent of job-stayers, on average, receive a nominal wage decline during a given year, far more than implied from an examination of base wages. We further document that the additional flexibility in terms of nominal wage adjustments provided by bonuses differs markedly throughout the base wage distribution. For those in the bottom quartile of the base wage distribution, bonuses are inconsequential. However, for those at the top of the base wage distribution, variation in annual bonuses is larger than that of annual base earnings. Finally, we show that fringe benefits also provide an additional but 
small margin of nominal wage adjustment for the average worker.

After documenting the difference between individual and aggregate wage rigidity, we examine the extent to which wages are able to adjust to shocks. We provide strong evidence that wage setting is state dependent. Even though nominal base wage cuts are very rare for job-stayers over our entire sample period, 6.6 percent of salaried workers received nominal base wage cuts during the Great Recession. Although the share of job-switchers, who are much more likely to see wage declines, fell during the recession, the aggregate propensity to receive a nominal base wage decline increased by 2.5 percentage points during the recession. Additionally, both the propensity to receive a bonus and the size of the bonus is tied to aggregate business cycle conditions. The share of bonuses in aggregate earnings fell by about one and a half percentage points during the Great Recession relative to the post 2012 period. We also document that industries hit hardest during the Great Recession (including both manufacturing and construction) were much more likely to cut nominal base wages during the recession relative to other industries. Finally, during the Great Recession, firms with declining employment were much more likely to reduce the nominal wages of their workers relative to firms with constant or increasing employment. These results suggests that any model with a constant fraction of wage adjustments will fail to match the wage setting patterns over a business cycle.

We end the paper with a discussion of how the wages of new hires adjust over the business cycle. In many models of firm employment dynamics it is the flexibility of new hire wages that determine employment fluctuations. It is hard to measure the flexibility of new hire wages at business cycle frequencies given the importance of selection in who works over the business cycle. ${ }^{3}$ Using our data, we can exploit how wages evolve for job-changers relative to job-stayers at business cycle frequencies. To do so, we benchmark job-changers who move from firm $i$ to firm $j$ between period $t-1$ and $t$ to a similar worker in firm $j$ in period $t-1$ based on their $t-1$ wages and demographic characteristics. We then document that the relative wages of the job-changer to their matched counterpart in $t$ is nearly invariant to business cycle conditions. Collectively, these results suggest that new hire wages evolve similarly to incumbent workers within a firm at business cycle frequencies. These results complement the findings in Hazell and Taska (2018) which documents that posted wages on a large online job board display similar adjustment patterns as the base wage changes of existing workers.

There is an existing literature on measuring nominal wage adjustments using either household surveys or administrative datasets. Instead of reviewing that literature collectively at

\footnotetext{
${ }^{3}$ For the importance of selection in determining the wage cyclicality, see Solon et al. (1994), Basu and House (2016), and Gertler et al. (2016).
} 
this point, we discuss the relevant literature in relationship to the results we present throughout the paper. This allows us to contrast our specific results with those from the literature. While some of our findings are qualitatively similar to results in the existing literature, they are often quantitatively different in magnitudes. These quantitative differences may have large consequences for the behavior of canonical models with wage rigidities. As we discuss throughout, differences between the results in our paper using the ADP data and other results in the literature are consistent with substantial measurement error in nominal wages in household surveys and the lack of high quality hours measures in administrative datasets.

Overall, our results emphasize that there is an important conceptual difference between compensation flexibility and contract flexibility. If contracts specify a base wage per unit of labor, as well as a schedule of bonuses as a function of performance, then the striking absence of base wage declines suggest that contracts may be subject to adjustment frictions, even if measured compensation per hour appears flexible. What's more, the ability for workers to move across firms is a source of aggregate nominal wage flexibility, and represents a key conceptual difference between nominal wage adjustment and output price adjustments. The patterns presented here urge the development of theories in which wage adjustment is state dependent and asymmetric, as such asymmetries will engender different aggregate responses to shocks in downturns and booms.

The paper proceeds as follows. Section 2 describes the ADP data in detail. Section 3 describes the allocation of worker compensation across base pay, bonuses and fringe benefits. Section 5 presents key facts about various measures of wage adjustments for job-stayers. Section 6 present wage change statistics for job-changers while Section 7 presents our measures of aggregate nominal wage adjustments. Sections 10 present evidence of state dependence at the aggregate and firm levels, respectively. Finally, Section 8 examines the cyclicality of new hire wages. Section 12 concludes.

\section{Data and Variable Definitions}

\subsection{Overview of ADP Data}

We use anonymized administrative individual panel data provided by ADP. ADP is a large, international provider of human resources services including payroll processing, benefits management, tax services, and compliance. ADP has over 650,000 clients worldwide, and currently covers payroll for over 20 million individual workers in the United States per month. The data to which we have access starts in May 2008 and extends through December 2016. During that period, ADP processed payroll for approximately one-eighth of the U.S. work- 
force.

The data contain monthly aggregates of anonymized individual paycheck information, as well as all relevant pieces of information needed for human resources management. Crucially, we observe, without measurement error, the statutory per-period payment rate for all employees. For hourly workers, this payment rate is simply the worker's hourly wage. For salaried workers, it constitutes the pay that the worker is contractually obligated to receive each pay period (weekly, bi-weekly, or monthly). Given the data is aggregated to the monthly level, the per-period payment rate is measured as of the last pay period of the month.

In addition to the administrative wage information, the data contain all other information that would appear on the worker's paycheck, such as the worker's gross earnings per pay period, taxes paid, and any taxable benefits provided by the firm. Additionally, the data contain other payroll information including whether the worker is paid hourly, the frequency at which the worker is paid and the number of hours worked during the month. For hourly workers, the exact number of hours worked is reported. For salaried workers, hours information is provided by the firm's HR administrator and often set to 40 hours. We also observe various additional geographic and demographic characteristics of a worker as well as details about the job, such as worker tenure, firm size, and industry. Selection into the ADP data is at the firm level. As a result, we can measure wage distributions within and across firms over time. ${ }^{4}$ Finally, the presence of consistently-defined anonymized worker identifiers permits the study of individual worker dynamics across ADP clients. However, given our sample size, movements from one ADP firm to another ADP firm are quite common. ${ }^{5}$

We make two major sample restrictions for our analysis. First, we restrict attention to prime age workers between 21 and 60 years old, inclusive. Second, ADP has two products separately targeted to firms with greater than or less than 50 employees. We only have access to data for firms with more than 50 employees throughout our sample period, and thus constrain our analysis to large employers.

The full dataset covers over 50 million unique individuals and over 141 thousand firms. To reduce computational burden, we create three random subsamples of the full data. The first

\footnotetext{
${ }^{4}$ Strictly speaking, our definition of a firm is an ADP-provided client code. This will usually be an autonomous firm, rather than any individual establishment. One possible exception to this rule arises if large conglomerates have multiple subsidiaries, all of which separately hire ADP to handle their payroll. In this case, each subsidiary would count as a separate ADP client. As a result, our ADP firms are a combination of both Census notions of firms and establishments.

${ }^{5}$ All worker and firm identifiers in the ADP data are unique and consistently defined over time. However, they are constructed in a way that all workers and firms remain anonymous for research purposes. Firm and worker names and detailed addresses as well as firm employer identification numbers and worker social security numbers are all purged from the data available to researchers. The ADP data use agreement prohibits using the data to explore wage patterns of any individual worker or firm.
} 
chooses one million unique employees, and follows them through their entire tenure in the sample across all firms for which they work. This is the primary dataset for analysis. Second, we separately draw a sample of 1 million workers who change jobs during our sample period ("job-changers"). These are workers who show up in multiple firms during their time in the ADP database. This will allow us to explore fully the patterns of wage changes for workers who switch between ADP firms. However, these two datasets are ill-suited to study questions at the firm level; we therefore construct a third subsample of three thousand unique ADP clients, drawing all workers from those firms in the process. The random employee-level, job-changer and firm-level subsamples remain large, with roughly 25 million, 27 million, and 68 million unique employee-month observations, respectively.

\subsection{Representativeness of ADP Data}

There are two areas of concern regarding the representativeness of the ADP data. First, the patterns we highlight in the paper apply only to firms with more than 50 employees. To the extent that the nature of nominal wage adjustments differs by firm size, the patterns we document within our sample may not be representative of the US economy as a whole. However, given that we show that there are only modest differences in nominal wage adjustments by firm size within our sample, we conjecture that any potential bias in our headline results from excluding firms with fewer than 50 employees is likely to be small. ${ }^{6}$

The second concern is whether ADP clients are representative of firms with more than 50 employees. According to industry reports, roughly 50 percent of US firms in recent years report outsourcing their payroll services to payroll processing companies. ${ }^{7}$ According to these same surveys, however, very large firms (firms with more than 10,000 employees) are less likely to outsource their payroll functions. As noted above, ADP processes payroll for about 20 million US workers per month. While ADP is the largest payroll processing company, the industry has many competing firms including Intuit, Workday, and Paychex.

Table 1 highlights the employment-weighted firm size distribution in our employee sample (column 1) and employees in our firm sample (column 2). For the results in this table, we pool our data over the entire 2008-2016 period. By design, we randomly drew 1 million employees for our employee sample and 3,000 firms for our firm sample. Our employee sample includes

\footnotetext{
${ }^{6}$ Furthermore, from 2013 onwards, we also have access to ADP's data for firms with fewer than 50 employees. These data reinforce that any potential bias from excluding small firms from the main results in our paper is likely to be minor. We discuss these results in detail in the Appendix Appendix C.3.

${ }^{7}$ According to a 2014 survey of 1,600 CFOs by Robert Half, a professional staffing company, 48 percent of US firms reported outsourcing their payroll services. See Thompson and McDonald (2014). Deloitte performed a smaller survey in 2014 and found that 56 percent of North American mid-size and large firms outsourced their payroll services.
} 
Table 1: Firm Size Distribution in ADP Samples and the BDS, Pooled 2008-2016 Data

\begin{tabular}{lccc}
\hline \hline & ADP Employee Sample & ADP Firm Sample & BDS Data \\
\hline Number of Employees & $1,000,000$ & $3,296,701$ & $\cdot$ \\
Number of Firms & 91,577 & 3,000 & $\cdot$ \\
Number of Observations & $24,831,244$ & $68,267,166$ & $\cdot$ \\
& & & \\
\% Firm Size: $50-499$ & 37.8 & 31.3 & 29.5 \\
\% Firm Size: $500-999$ & 13.6 & 13.9 & 7.3 \\
\% Firm Size: $1000-4999$ & 25.1 & 22.2 & 17.5 \\
\% Firm Size: $\geq$ 5000 & 19.7 & 32.5 & 45.6 \\
\hline \hline Notes: Table reports the share of employees in firms of various sizes in our random samples of the \\
ADP data, stratified at the employee (Column 1), and firm levels (column 2). Column 3 reports \\
the associated employee-weighted firm size distribution reported in the Census' Business Dynamics \\
Statistics (BDS) data. All numbers span the period 2008-2016. In addition, the first three rows \\
show the number of unique employees, firms, and observations in each of our ADP subsamples.
\end{tabular}

roughly 91,500 distinct firms while our firm sample includes roughly 3.3 million distinct employees. The number of actual observations is much larger for each sample because we observe employees for multiple months. For our employee sample, we track employees across all months between 2008 and 2016 that they are employed at any ADP firm. For our firm sample, we track all employees in that firm across all months that they remain employed at that firm.

For comparison, column 3 of Table 1 includes the firm size distribution from the U.S. Census's Business Dynamics Statistics (BDS) over the same time period restricting our attention to only firms with more than 50 employees. ${ }^{8}$ As seen from the table and consistent with industry surveys, ADP under-represents very large employers (those with at least 5,000 employees). According to BDS data, nearly 46 percent of all employment in firms with more than 50 employees is in firms with more than 5,000 employees. The ADP data only has about 20 percent of employment (in our employee sample) in firms with more than 5,000 employees. ${ }^{9}$ As noted above, some of this difference also results from the fact that the ADP definition of a firm is different from Census definitions.

To account for the concern that the data do not perfectly represent the universe of all U.S. firms with at least 50 employees, all subsequent analyses have been weighted so as to match the BDS's firm size by industry mix of employment shares for firms with greater than 50

\footnotetext{
${ }^{8}$ According to BDS data, $72 \%$ of all U.S. employment during this time period is in firms with more than 50 employees.

${ }^{9}$ We also explore how the industry distribution of the ADP sample compares to the industry distribution in the BDS. We are unable to report ADP's precise industry distribution for disclosure reasons. The ADP sample has a slight over-representation amongst the manufacturing and broad service sectors, and a complementary underweight in retail trade, construction, and agriculture.
} 
employees. We compute our weights for each year between 2008 and 2016. By re-weighting the data, we control for sample selection along these key observable dimensions. Although there may yet remain selection into the sample along unobservable dimensions, we consider these potential selection issues to be small once controlling for firm size and industrial mix.

Given this is the first paper using the ADP data, a deeper discussion of the representativeness of the ADP sample is warranted. We have relegated much of this discussion to the Online Appendix. In particular, we benchmark the demographic composition of the ADP sample to that of the CPS along a variety of dimensions. Additionally, we compare annual earnings dynamics in our ADP sample for people who remain continuously employed with the same firm for two years to the earnings dynamics in Guvenen et al. (2014) for a similarly defined sample. Further, we compare both levels and time series trends in the average hourly wage for workers paid hourly between our ADP sample and a similar CPS sample. We also examine patterns in nominal wage adjustments by firm size to explore potential biases from our data being under-representative of both really small and really large firms. Finally, we show the unweighted results for many of the paper's key findings. After performing all of these benchmarking exercises, we are confident that the ADP data provides a representative picture of nominal wage adjustments for U.S. workers over the 2008 to 2016 period.

\section{The Nature of US Worker Compensation}

The ADP data includes many detailed administratively recorded measures of worker compensation. In this section, we describe the composition of worker compensation. We first exhibit the overwhelming importance of base earnings, before considering the size of bonuses and fringe benefits in workers' compensation.

\subsection{Base Wages and Base Earnings}

Employers participating in the ADP payroll services are required to report the contractually obligated per-period wage rate for each worker. For workers who are paid hourly, this is the workers' hourly wage. All salaried workers have an administrative field recording their weekly, bi-weekly or monthly contracted salary rate depending on the frequency of their pay period. We refer to the contractually obligated per-period wage rate as a worker's "base wage."

A separate field in the data reports workers' administrative "monthly gross earnings" (excluding employer-provided fringe benefits). A worker's base pay is only one part of their monthly gross earnings. During a given month, a worker may also receive tips, commissions, 
overtime payments, performance pay, bonuses, cashed-out vacation days and meal and travel reimbursements. ${ }^{10}$ Monthly gross earnings is literally the sum of all paychecks (before taxes) earned by the worker during the month. To isolate the importance of base wages in worker earnings, we define the concept of a worker's "monthly base earnings" using information on their base wage. If the worker is an hourly worker, their monthly base earnings is their base wage times the total number of hours worked during the month. If the worker is a salaried worker, their monthly base earnings is their base wage times the number of paychecks received during the month. Any difference between a worker's monthly gross earnings and their monthly base earnings is the result of the worker earning some combination of bonuses, tips, overtime, reimbursements or other non-standard payments during the month.

Table 2 shows the distribution of base earnings out of total gross earnings for U.S. workers during the 2008-2016 period. The table has five columns. The first column uses our total employee sample and computes the share of total monthly base earnings out of monthly total gross earnings. As seen from column 1, the median worker in a typical month has all of their earnings coming from their base earnings. However, 25 percent of workers have about six percent of their monthly earnings coming from sources other than their base pay while 10 percent of workers have about one-fifth of their monthly earnings coming from sources other than their base pay.

Non-standard payments are not likely to accrue every month for a given worker. To see how important these sources are for a typical worker, we aggregate our data to calendar years. For this analysis, we restrict our analysis to workers who remain continuously employed with the same firm for all twelve calendar months of a given year. We refer to this sample as our "full-year" employee sample. Column 2 shows that our monthly analysis does not change at all after restricting attention to the full year sample. Column 3 shows the share of annual gross earnings that come from annual base earnings. To compute annual measures of both gross earnings and base earnings, we simply sum the monthly measures over the twelve calendar month. ${ }^{11}$ About one-quarter of all workers receive essentially all of their annual compensation from base earnings. The median worker earns only 3.8 percent of their annual earnings from sources other than their base pay. This suggests that for most workers, base pay is their primary form of compensation. However, for some workers, other forms of compensation (e.g., bonuses, commissions, tips, overtime) comprise a more substantive portion of their annual earnings. Ten percent of workers earn at least 20 percent of their

\footnotetext{
${ }^{10}$ The fact that meal and travel reimbursements can show up in workers' paychecks implies that there is not a one-to-one mapping between monthly gross earnings in our dataset and monthly W-2 earnings. We do not have a worker's W-2 earnings in the data provided to us by ADP.

${ }^{11}$ Note, given that our data starts in May 2008, we cannot make an annual measure for 2008. Our full-year sample includes data from 2009-2016.
} 
Table 2: Share of Base Earnings out of Gross Earnings, 2008-2016

\begin{tabular}{lccccc}
\hline \hline & $\begin{array}{c}\text { Monthly } \\
\text { Share }\end{array}$ & $\begin{array}{c}\text { Monthly } \\
\text { Share }\end{array}$ & $\begin{array}{c}\text { Annual } \\
\text { Share }\end{array}$ & $\begin{array}{c}\text { Annual } \\
\text { Share }\end{array}$ & $\begin{array}{c}\text { Annual } \\
\text { Share }\end{array}$ \\
\hline $10^{\text {th }}$ Percentile & $80.6 \%$ & $80.8 \%$ & $81.6 \%$ & $85.7 \%$ & $75.2 \%$ \\
$25^{\text {th }}$ Percentile & $93.9 \%$ & $93.9 \%$ & $90.3 \%$ & $92.1 \%$ & $86.9 \%$ \\
Median & $100 \%$ & $100 \%$ & $96.2 \%$ & $96.9 \%$ & $94.7 \%$ \\
$75^{\text {th }}$ Percentile & $100 \%$ & $100 \%$ & $99.4 \%$ & $99.4 \%$ & $99.5 \%$ \\
$90^{\text {th }}$ Percentile & $100 \%$ & $100 \%$ & $100 \%$ & $100 \%$ & $100 \%$ \\
& & & & & \\
Full Year Restriction & No & Yes & Yes & Yes & Yes \\
Type of Worker & All & All & All & Hourly & Salaried \\
Sample Size (millions) & 18.25 & 9.01 & 0.75 & 0.46 & 0.28 \\
\hline \hline
\end{tabular}

Notes: Table shows the distribution of the share of worker base earnings out of worker gross earnings. Columns 1 and 2 report data for each worker-month pooled over our 2008-2016 sample. Columns 3, 4 and 5 report data for each worker-calendar year over our 2009-2016 sample. Columns 2-5 restrict our data to include only workers who remain employed continuously with the same firm over the entire 12 calendar months of a given year. Columns 4 and 5 look separately at hourly workers and only salaried workers. See text for additional details.

annual earnings from sources other than their base pay. Columns (4) and (5) show patterns separately for workers paid hourly and salaried. Base earnings are an especially large share of gross earnings for hourly workers.

\subsection{Measuring Overtime, Bonuses, and Commissions}

Ideally, one would decompose workers' "residual earnings" - gross earnings less base earnings - into various sub-components. However, the ADP data is not well-suited for such disaggregation. Firms are not required to separately report the different potential subcomponents that comprise residual earnings. Despite the limitation, we make four refinements to our residual earnings measures. First, we impute the amount of monthly overtime premiums paid to hourly workers using an often-reported "overtime earnings" field in the data. For hourly workers, therefore, we can create a measure of monthly residual earnings net of overtime payments. ${ }^{12}$

Second, we define large residual earnings to be any residual earnings net of overtime that accrue to a worker in a given month that exceeds $1 \%$ of their annual earnings. For example, if a worker earned $\$ 50,000$ during a given calendar year, we would classify that worker as

\footnotetext{
${ }^{12}$ We discuss this imputation procedure in greater detail in Appendix 3.2. Firms are asked to report total hours worked (inclusive of overtime) and total earnings from hourly work (inclusive of overtime). Comparing these measures to our measures of base earnings allows for a crude imputation of overtime. Consistent with anecdotal evidence, these overtime wage rates center on 1.5 and 2 times base wage rates.
} 
having large residual earnings during a given month if residual earnings net of overtime pay exceeded $\$ 500$ during that month. By making this restriction, we exclude any small payments made to the worker during a given month such as small meal reimbursements or small measurement error in our overtime imputation.

Third, we compute the frequency of months a worker receives large residual payments during a given year. We define a worker to be a "commission worker" if they receive large residual earnings net of overtime in four or more calendar months during a given year. We are interpreting "commission workers" broadly in that these workers could have large residual payments in four or more months during a given year due to sufficiently frequent commissions, tips, performance pay, mis-measured overtime pay, or even large meal and travel reimbursements. We can then segment workers into "non-commission workers" and "commission workers". According to this definition, roughly 10 percent of workers each year during our sample can be classified as commission workers.

Finally, for non-commission workers, we define a worker as having received a "bonus" if that worker received a large residual earnings payment net of overtime in at least one month but no more than three months during a given calendar year. Again, our definition of bonus is broad in that it applies to any large infrequent extra non-overtime payments received by workers during a year. During our sample period and given our definition, roughly 30 percent of non-commission workers receive a bonus during a given year. ${ }^{13}$

Table 3 shows the importance of annual base pay and bonuses as a share of annual earnings for non-commission workers. The first two columns show results pooling together hourly and salaried workers. The remaining columns show the same patterns for hourly and salaried workers separately. Removing the 10 percent of workers we define as commission workers results in much higher share of base pay in annual earnings. For the median noncommission worker, nearly 98 percent of their annual earnings is in base pay. Furthermore, nearly all remaining compensation for non-commission workers is in what we classify as bonuses. Specifically, for the median worker, over $99 \%$ of all annual gross earnings are base earnings and what we classify as bonuses. This is important in that for the rest of the paper we are going to focus on nominal wage adjustments of base pay and bonuses. Doing so, captures essentially all of the compensation for most non-commission workers. The remaining gross earnings for most non-commission workers is in overtime pay and other small infrequent residual earnings payments. Throughout the paper, we present results on nominal wage adjustments separately for both non-commission and commission workers.

\footnotetext{
${ }^{13}$ It should be noted that most of these extra payments occur in December, February and March suggesting that many of them are likely linked to annual bonuses.
} 
Table 3: Share of Annual Base Earnings and Bonuses out of Annual Gross Earnings, 20092016, Non-Commission Workers

\begin{tabular}{|c|c|c|c|c|c|c|}
\hline & & 11 & & arly & Salc & ried \\
\hline & & Share & & Share & & Share \\
\hline & Share & Base+ & Share & Base+ & Share & Base+ \\
\hline & Base & Bonus & Base & Bonus & Base & Bonus \\
\hline $10^{t h}$ percentile & $89.7 \%$ & $93.5 \%$ & $91.6 \%$ & $92.8 \%$ & $86.6 \%$ & $96.0 \%$ \\
\hline $25^{\text {th }}$ percentile & $93.8 \%$ & $96.8 \%$ & $94.8 \%$ & $95.7 \%$ & $91.6 \%$ & $99.0 \%$ \\
\hline Median & $97.5 \%$ & $99.3 \%$ & $97.8 \%$ & $98.5 \%$ & $96.5 \%$ & $100 \%$ \\
\hline $75^{\text {th }}$ percentile & $99.7 \%$ & $100 \%$ & $99.6 \%$ & $99.8 \%$ & $100 \%$ & $100 \%$ \\
\hline $90^{\text {th }}$ percentile & $100 \%$ & $100 \%$ & $100 \%$ & $100 \%$ & $100 \%$ & $100 \%$ \\
\hline Sample Size (thousands) & 611 & 611 & 378 & 378 & 222 & 222 \\
\hline $\begin{array}{l}\text { Notes: Table shows the distr } \\
\text { earnings plus annual bonuses } \\
\text { sample of non-commission wo } \\
\text { twelve months of a calendar y } \\
\text { paid hourly (columns } 3 \text { and } 4\end{array}$ & of th & $\begin{array}{l}\text { hare of } \\
\text { vorker } \\
\text { ain con }\end{array}$ & r annu & $\begin{array}{l}\text { base ea } \\
\text { We restr } \\
\text { oyed wit }\end{array}$ & and ar & $\begin{array}{l}\text { ual base } \\
\text { on to our } \\
\text { m for all } \\
\text { workers }\end{array}$ \\
\hline
\end{tabular}

\subsection{Employer-Provided Fringe Benefits}

Lastly, we create a broader measure of worker compensation that includes employer-provided fringe benefits. The data contain all forms of fringe benefit that would appear on an employee's paycheck, including employer-provided health insurance and contributions to a retirement plan or pension - such as a $401(\mathrm{k})$ or Roth IRA - made by the employer. ${ }^{14}$ Us- $^{-}$ ing these data, we create a measure of "annual fringe benefits" by summing the monthly employer-provided health benefits and retirement contributions over all months of a year. The fringe benefit measures were not-consistently reported prior to 2012. Starting in 2012, as part of the Affordable Care Act, employers were required to report their contributions to employee health benefits. Given this, when analyzing measures of broader compensation, our analysis is limited to workers who remain continuously employed with the same firm during the 2012-2016 period.

Using these measures, we create a measure of a worker's "total annual compensation" by summing their annual gross earnings with their annual employer-provided fringe benefits. Table 4 shows the distribution of the share of total compensation that is in fringe benefits for all workers in our full-year employee sample. ${ }^{15}$ Fringe benefits accounts for $8.2 \%$ of

\footnotetext{
${ }^{14}$ We exclude all tax measures from our analysis including employer paid payroll taxes. Additionally, we note that our fringe benefit and bonus measures do not include stock options. ADP has data on when stock options are cashed in (for tax reasons), but not when the options were granted.

${ }^{15}$ The results between the full sample and the commission sample were nearly identical.
} 
Table 4: Share of Fringe Benefits out of Total Compensation, 2012-2016 Period

\begin{tabular}{lccc}
\hline \hline & All & Hourly & Salaried \\
\hline $10^{t h}$ percentile & $0.0 \%$ & $0.0 \%$ & $0.0 \%$ \\
$25^{t h}$ percentile & $1.3 \%$ & $0.0 \%$ & $4.4 \%$ \\
Median & $8.2 \%$ & $6.5 \%$ & $9.5 \%$ \\
$75^{t h}$ percentile & $17.1 \%$ & $18.3 \%$ & $15.9 \%$ \\
$90^{t h}$ percentile & $25.1 \%$ & $27.1 \%$ & $22.2 \%$ \\
& & & \\
Mean Total Fringe Share & $10.7 \%$ & $10.6 \%$ & $10.8 \%$ \\
Mean Health Fringe Share & $7.9 \%$ & $8.7 \%$ & $6.7 \%$ \\
Mean Pension Fringe Share & $2.8 \%$ & $2.0 \%$ & $4.0 \%$ \\
& & & \\
Sample Size (Thousands) & 630 & 370 & 260 \\
\hline
\end{tabular}

Notes: Table shows the distribution of the share of worker fringe benefits out of total worker compensation during the 2012-2016 period for all workers in our full time employee sample (column 1) and then separately for hourly and salaried workers (columns 2 and 3 ).

the median worker's total compensation, but there is large variation around this number, with $10 \%$ of workers receiving more than $25 \%$ of their compensation through fringe benefits, and many workers receiving no fringe benefits at all. Hourly workers tend to receive fewer fringe benefits than do salaried workers: the median hourly worker has $6.5 \%$ of their total compensation in fringe benefits, compared with $9.5 \%$ for salaried workers, However, the right tail of fringe benefits for hourly workers is thicker for hourly workers than for salaried workers, with the 90th percentile of hourly workers receiving $27.1 \%$ of their compensation from special compensation, compared with $22.2 \%$ for salaried workers. Encouragingly, the numbers presented in this table match those found by the BLS in their Employer Cost for Employee Compensation (ECEC) reports. For example, the June 2016 report finds that $7.6 \%$ of workers' total compensation is accounted for by the cost of health insurance, and $3.9 \%$ is accounted for by retirement and savings account contributions. ${ }^{16}$

\subsection{Heterogeneity in Bonuses and Fringe Benefits Across Workers}

The left panel of Figure 1 shows the share of annual bonus income out of annual total earnings sorted by workers' base wage percentile. ${ }^{17}$ As with the results above, we exclude

\footnotetext{
${ }^{16}$ See, for instance https://www.bls.gov/news.release/ecec.nro.htm. The aggregate fringe benefit share does not match exactly, as the BLS includes paid leave, bonuses, and legally-required benefits such as social security payments, the first two of which will be included in our measure of gross earnings.

${ }^{17}$ To make the base wage percentile, we combine data on both hourly and salaried workers. For hourly workers, we use their base hourly wage. For salaried workers, to put things in the same hourly wage units, we divided their base weekly earnings by 40 hours.
} 
Figure 1: Bonus and Fringe Benefit Share by Employee Base Wage Percentile, Two-Year Job-Stayers, Excluding Commission Workers

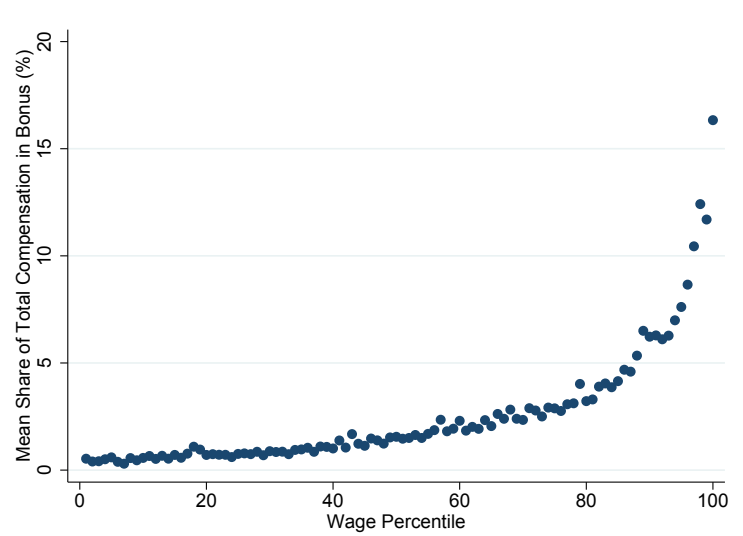

Panel A: Share in Bonus Out of Total Earnings

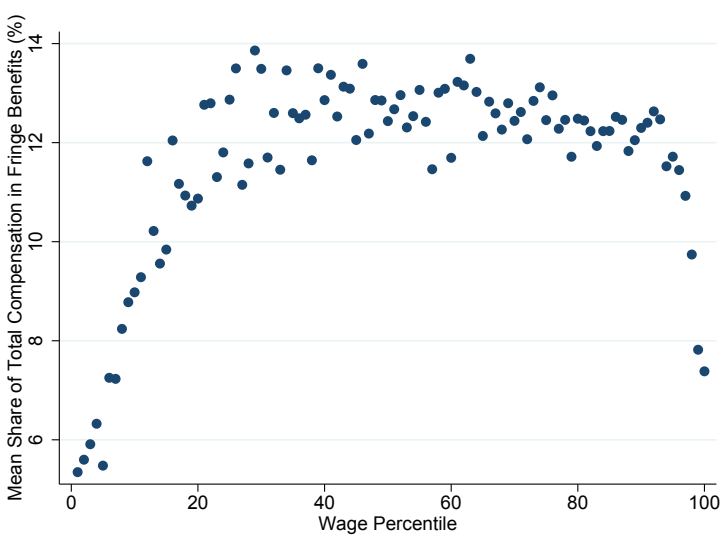

Panel B: Share in Fringe Benefits Out of Total Compensation

Notes: Panel A shows the share of bonus earnings out of total earnings by worker percentile within the base earnings distribution. Panel B shows the share of fringe benefits out of total compensation by worker percentile within the base earnings distribution. Sample restricted to our sample of job-stayers who remain in the sample for two full calendar years. Commission workers are excluded.

commission workers. Workers at the lower end of the base wage distribution receive, on average, only less than $0.5 \%$ of their annual earnings in bonuses. The share of earnings in bonuses increases monotonically throughout the wage distribution. The median worker earns about $2 \%$ of their annual earnings in bonuses. Systematically, workers at the top of the wage distribution earn a substantial amount of their annual earnings in bonuses. Therefore, while annual bonuses are not an important form of compensation for most workers, they are substantial for high wage workers.

The right panel of the figure shows the share of annual fringe benefits provided by the employer out of a worker's annual total compensation (earnings plus fringe) as a function of the worker's base wage percentile. Fringe benefits are much less important for lower wage workers (below the 20th percentile). However, from the 20th percentile through the 95th percentile of the wage distribution, the share of total compensation in fringe is roughly constant in the 12 to 14 percent range. For top wage earners, fringe becomes a smaller fraction of total compensation. This is likely because fringe benefits are not usually provided on bonus income and because tax exempt employer-provided retirement contributions are capped. 


\section{Setting the Stage: Base Wages vs. Bonuses}

The remainder of the paper presents a host of new statistics concerning wage adjustment in the United States. We break aggregate earnings per hour fluctuations into three components: base wage adjustment for job-stayers, base wage adjustment for job-changers, and bonus adjustment for job-stayers. Throughout, we will be purposefully agnostic as to which moments should drive aggregate fluctuations, preferring instead to let modelers pick the relevant numbers for their calibration based on their specific model structure. In this section, however, we provide suggestions on the importance of each margin of adjustment, borrowing insights and intuition from both the wage and price setting literatures.

A large literature has developed arguing that the rigidity of job-changers' and new hires' wages determine fluctuations in employment. add some citations This is because firms and workers enter into long-term employment relationships, rendering the wage of new hires marginal for the decision of firms to post vacancies and the decision of unemployed workers to search for a job. As is highlighted in Kudlyak (2014), given the nature of such long-term employment relationships, it is not the spot wage of new hires that matters for employment fluctuations but rather the user cost of labor. The user cost of labor is defined as the expected present value of costs to the firm associated with adding an additional worker in period $t$ rather than waiting and adding the worker in period $t+1$. In existing frameworks, there is no distinction between base wages and bonuses in the definition of the user cost. Indeed, it is not trivial to define the notion of a user cost when bonuses are used to incentivize unobserved effort, as is assumed in many models of optimal contracting. For this reason and given our relatively short sample, we elect not to measure user cost rigidity directly in this paper.

Despite not directly measuring the user cost of labor, it is worth discussing which of our wage measures is conceptually better linked to the user cost notion. A core component of the user cost is the present value of wages. Given this, it is important to highlight the persistence of our various wage concepts. To consider which type of wage component is most persistent, we estimate autocorrelation coefficients for our various wage measures. Specifically we estimate OLS regressions of the form:

$$
y_{i t}=\rho y_{i t-1}+\alpha_{i}+\epsilon_{i t}
$$

where $i$ indexes a worker-firm pair, $t$ represents a year and $\alpha_{i}$ is a job fixed effect. $y_{i t}$ represents the value of a particular wage measure for job $i$ in year $t$. For this exercise we use our sample of who remain continuously employed on the same job (job-stayers) for two consecutive calendar years. 
Table 5: Annual Persistence of Bonuses vs Standard Wage, sample of full-year job-stayers, 2009-2016

\begin{tabular}{lcccc}
\hline \hline & $\begin{array}{c}\text { Log } \\
\text { December } \\
\text { Base wage } \\
(1)\end{array}$ & $\begin{array}{c}\text { Log } \\
\text { Bonus } \\
(2)\end{array}$ & $\begin{array}{c}\text { Linear } \\
\text { Bonus } \\
(3)\end{array}$ & $\begin{array}{c}\text { Share } \\
\text { Bonus } \\
(4)\end{array}$ \\
\hline \multirow{4}{*}{$y_{i, t-1}$} & $0.775^{* * *}$ & 0.016 & 0.018 & $-0.054^{* *}$ \\
& $(0.012)$ & $(0.016)$ & $(0.088)$ & $(0.023)$ \\
Job FE & Yes & Yes & Yes & Yes \\
Observations & 586,023 & 145,904 & 586,023 & 586,023 \\
$R^{2}$ & 0.995 & 0.926 & 0.764 & 0.780 \\
\hline \hline
\end{tabular}

Notes: Table reports OLS-estimated AR(1) coefficients from equation 1. White heteroskedasticity robust standard errors clustered at the employee-level reported in parentheses. ${ }^{* * *},{ }^{* *}$, and ${ }^{*}$ represent coefficients are statistically different from 0 at the $10 \%, 5 \%$, and $1 \%$ levels, respectively. We use the employee sample restricting our analysis to workers who remain continuously employed with the same firm for two consecutive calendar years.

Table 5 reports the estimated autocorrelation coefficient $\rho$ of various wage measures at the individual level. We explore the persistence of log base wages (first column) and various specifications of bonuses (columns 2 through 4). As seen from the table, base wages have an annual autocorrelation of 0.775. By comparison, bonuses appear to be almost i.i.d., whether we consider log-linear or linear specifications. Indeed regressing the share of pay in bonuses (column 4) on its lagged value yields a negative coefficient, suggesting that high bonus years tend to be followed by low bonus years. These results suggests that base wage adjustments may be a far better measure of permanent wage adjustments than are bonus payments. Given this, the ability to adjust base wages are likely going to be much more important for changes in the user cost of labor than the ability to adjust bonuses.

Bonuses could still be an important margin of adjustment if they fluctuated to match high-frequency productivity shocks. However, this is not the case. The strong seasonality of bonus payments reduces their usefulness as a source of flexibility. Conditional on receiving a bonus, most workers only receive a bonus once a year. Most bonuses are concentrated in only a few months (e.g., December, February and March). Indeed, at the firm-level, 28\% of workers receive a bonus in their employer's most common bonus-granting month, which is large since just $31 \%$ of workers receive a bonus in a given year. While bonuses may provide downward adjustments in workers' total annual compensation (as we highlight below), they appear rigid over short time horizons.

These pieces of evidence lead us to conclude that base wage rigidity more closely resembles 
what we term "contract rigidity" - the ability of firms to adjust the terms governing their long-term relationship with their employees, which consist of a base wage and a bonus schedule as a function of performance - and thus is a more appropriate measure of rigidity to use for models seeking to understand aggregate employment fluctuations over the cycle. The ability of our data to measure base wages separately from other forms of compensation is thus a key contribution of this paper. Whether to use incumbent base wages (Section 5), job-changer base wages (Section 6), an aggregate of the two (Section 7), or new hire base wages (Section 8) is model dependent. For instance, Gertler et al. (2016) put forth a model in which the rigidity of incumbents' wages is the key factor in determining cyclical fluctuations, while Pissarides (2009) makes a compelling case for the importance of new hire wages.

An analogue to the base wage versus bonus distinction can be drawn from the output price setting literature. Eichenbaum et al. (2011) show that nominal rigidities take the form of inertia in reference prices and costs. As a result, short-term sales of output prices may be ignored for assessing the impact of nominal rigidities on aggregate fluctuations. Indeed, much of the empirical literature has excluded sales from their measure of price adjustments (Nakamura and Steinsson, 2008) or directly incorporated a differential adjustment cost for sales relative to reference prices (Kehoe and Midrigan, 2008; Midrigan, 2011). Given the transient nature of bonuses, it is natural to liken them to a "sale" in the pricing literature.

This does not imply that bonuses are unimportant for macroeconomics. Recent studies of average hourly earnings adjustments (Barattieri et al., 2014; Daly and Hobijn, 2014; Jardim et al., 2019; Kurmann and McEntarfer, 2018) have great value for different questions and models. Studies looking to understand earnings dynamics and the stagnation of average hourly earnings, or which care about temporary earnings shocks will naturally require earnings measures inclusive of bonuses. Furthermore, fuller models of nominal contract rigidity, which incorporate explicit optimal contracts inclusive of bonuses, or models of dynamic contracts, require knowledge of both base and bonus compensation. In essence, bonuses are an important component of the spot wage for labor. To the extent that spot wages matter for macroeconomics - if, for instance, firms' are subject to period-by-period financing constraints (Schoefer, 2016) or households are liquidity constrained (Kaplan and Violante, 2014) - then so too will aggregate wage adjustments inclusive of bonuses.

Given these issues, we begin the paper by documenting how base wages evolve for both job-stayers, job-changers, and new hires. We then discuss the evolution of wage measures inclusive of bonus variation, whose usefulness will be model-dependent. 


\section{Nominal Base Wage Adjustments for Job-Stayers and Job-Changers}

This section explores the nature of nominal base wage adjustments for workers who remain continuously employed in the same job. We use our employee sample and define "jobstayers" as those workers who remain continuously employed with the same firm between the two periods where the nominal wage is being measured. We present moments of nominal base wage adjustment at the monthly, quarterly and annual frequencies. For the monthly, quarterly and annual samples, we ensure that workers are continuously employed with the same firm for one, three and twelve consecutive months, respectively.

Figure 2 plots the distribution of 12-month nominal base wage changes for all job-stayers pooled over all years of our sample. As discussed above, base wages make up essentially all annual compensation for most workers. Panel A plots the distribution for hourly workers, while Panel B plots the distribution for salaried workers. Four key observations are apparent from the figure. First, a large share of workers - 33\% of hourly and 35\% of salaried - do not receive a nominal base wage change in a given year. Second, the patterns of nominal base wage adjustments for hourly workers and salaried workers are nearly identical. Given this, we often pool the data for hourly and salaried workers together going forward when describing base wage adjustments. Third, there is a clear asymmetry in the base wage change distribution, with the overwhelming majority of changes being wage increases. Only 2.4 percent of workers (combining hourly and salaried) in the U.S. who remained continuously employed with the same firm for 12 months received a nominal base wage decline. Of the roughly $66 \%$ of all individuals who receive a nominal base wage change over a given 12month period, only $3.6 \%$ received a nominal base wage cut $(2.4 / 66)$. Finally, there are very few small nominal base wage changes for either hourly or salaried workers. Just $8.6 \%$ of all workers received a nominal base wage change of between 0.1 and 2 percentage points, compared with $27.1 \%$ receiving between 2 and 4 percentage points. This missing mass of very small wage changes is consistent with the random menu cost models that are prevalent in the price setting literature.

Table 6 provides a set of summary moments on the probability of base wage increases and base wage declines for three frequencies: monthly, quarterly and annual. The annual frequencies correspond to the underlying data shown in Figure 2. While the asymmetry between nominal wage increases and nominal wage cuts is a feature of many existing em-

pirical papers (see, e.g. Lebow et al. (2003); Kahn (1997); Card and Hyslop (1997)), the results in Figure 2 are quantitatively different from much of the existing literature. As we highlight below, measurement error in household data sets has resulted in estimates of nom- 
Figure 2: 12-Month Nominal Base Wage Change Distribution, Job-Stayers

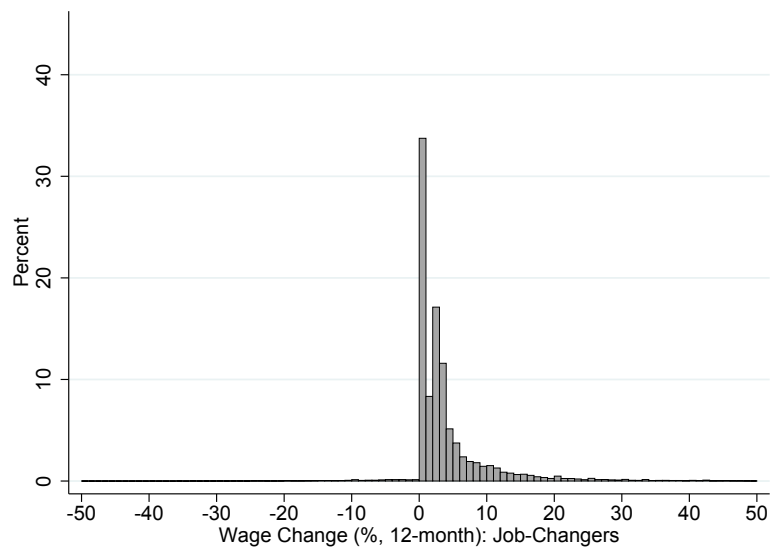

Panel A: Hourly Workers

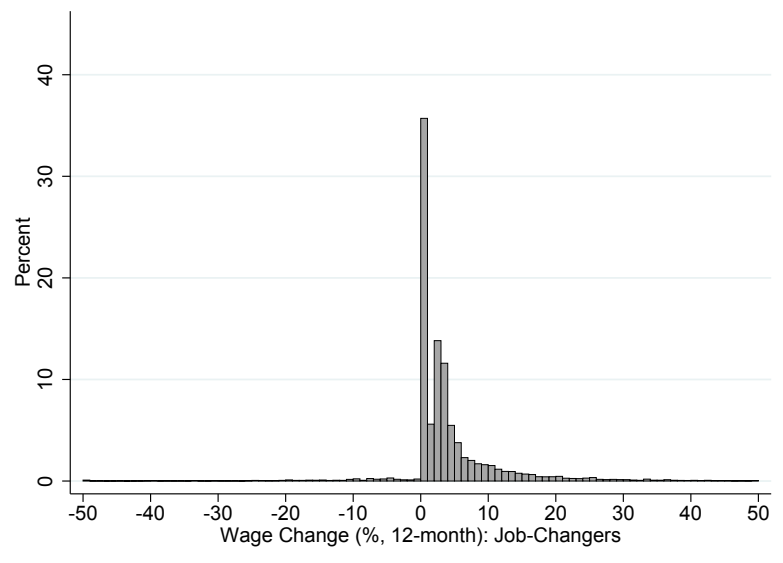

PANel B: SAlaried Workers

Notes: Figure shows the annual change in nominal base wages for workers in our employee sample (including commission workers) who remain employed on the same job.

inal wage adjustments (both up and down) that are higher than our administrative payroll data suggest. In addition, the missing mass of small wage changes urges models of state dependent wage adjustment, which we explore in more depth in Section 10. Again, because of measurement error, this missing mass has been difficult to detect in prior work. Finally, most existing studies measure wages inclusive of both base wages and bonuses. As we also highlight below, the frequency of downward adjustment of base wages is quite different than the frequency of downward adjustment of wage measures inclusive of bonuses.

The patterns of nominal wage adjustments for job-stayers are fairly robust across workers who are compensated in different ways. In the Appendix Appendix C, we show that the patterns in Figure 2 are nearly identical if we restrict our sample to only non-commission workers, only commission workers, only non-commission workers who receive a bonus and only non-commission workers who do not receive a bonus. These findings suggest that base wage adjustments do not differ across workers who receive other types of compensation. Additionally, we show that the patterns of base wage adjustment are nearly identical for those workers who are paid hourly and who have substantive movements in monthly hours worked throughout the year. Even for workers whose hours appear allocative, there are essentially no nominal base wage cuts and roughly one-third of workers do not receive a year-over-year nominal base wage increase.

Table 7 shows additional moments of the base wage change distribution. For this table, we only report results pooling together both hourly and salaried workers given the frequency of 
Table 6: Probability of Base Wage Change, Pooled 2008-2016 Sample of Job-Stayers

All Workers Hourly Salaried

(1)

$\underline{\text { Annual }}$

Probability of Positive Base Wage Change (\%)

63.9

$65.3 \quad 61.6$

Probability of Negative Base Wage Change (\%)

2.4

1.8

3.6

Quarterly

$\begin{array}{llll}\text { Probability of Positive Base Wage Change (\%) } & 18.5 & 19.5 & 16.7\end{array}$

Probability of Negative Base Wage Change (\%)

0.9

0.7

1.3

Monthly

$\begin{array}{lllll}\text { Probability of Positive Base Wage Change (\%) } & 6.3 & 6.6 & 5.8\end{array}$

Probability of Negative Base Wage Change (\%) $\quad 0.6 \quad 0.3 \quad 0.6$

Notes: Table shows the frequency of base wage increases and base wage decreases at different horizons for our sample of job-stayers during the 2008-2016 period. The first column pools together hourly and salaried workers while the second and third columns, respectively, show the frequency of changes for hourly and salaried workers separately. The top panel shows results at the annual horizon while the middle and bottom panels show results at the quarterly and monthly horizons. We use our full employee sample for this analysis (including commission workers).

Table 7: Base Wage Change Statistics, Pooled 2008-2016 Sample of Job-Stayers

\begin{tabular}{lccc}
\hline \hline & Monthly & Quarterly & Annual \\
\hline Mean Unconditional Change (\%) & 0.3 & 1.0 & 3.9 \\
Median Unconditional Change (\%) & 0.0 & 0.0 & 2.4 \\
Standard Deviation of Unconditional Change (\%) & 2.6 & 3.7 & 6.5 \\
& & & \\
Mean Wage Change (\%) & 5.2 & 5.1 & 5.8 \\
Median Wage Change (\%) & 3.1 & 3.1 & 3.4 \\
Standard Deviation of Wage Change (\%) & 8.0 & 6.5 & 7.0 \\
Mean Change, Conditional on Positive (\%) & 6.2 & 5.7 & 6.3 \\
Median Change, Conditional on Positive (\%) & 3.3 & 3.3 & 3.5 \\
Stan. Dev. Change, Conditional on Positive (\%) & 7.7 & 6.4 & 7.0 \\
& & & \\
Mean Change, Conditional on Negative (\%) & -10.7 & -8.7 & -7.3 \\
Median Change, Conditional on Negative (\%) & -8.3 & -7.7 & -6.6 \\
Stan. Dev. Change, Conditional on Negative (\%) & 8.1 & 5.8 & 4.6 \\
\hline \hline
\end{tabular}

Notes: Table shows moments of the wage change distribution for different horizons for a sample of job-stayers in the ADP data between 2008 and 2016. For this table, we use our employee sample and pool together hourly and salaried workers. All data are weighted to be nationally representative of sample of workers working in firms with more than 50 employees. Higher order moments of the wage change distribution are presented in Appendix Table A2. 
adjustment distributions were similar between the two groups. ${ }^{18}$ During this period, mean and median nominal base wage growth for workers who remain on the same job equaled 3.9 percent and 2.4 percent, respectively. ${ }^{19}$ Conditional on a base wage change occurring, annual mean and median base nominal wage growth was 5.8 and 3.4 percent. A key statistic we will focus on throughout the paper is the standard deviation of nominal wage growth. Unconditionally and conditional on a base wage change occurring, the standard deviation of annual nominal base wage growth during the full 2008-2016 period was 6.5 percent and 7.0 percent, respectively. ${ }^{20}$ Additionally, conditional on a positive base wage change occurring during a 12 month period, the mean and median size of the increase was 6.3 and 3.5 percent. The fact that the mean is much higher than the median reinforces the fact that some workers receive very large nominal base wage changes on the job, perhaps due to promotions. The mean and median size of a base wage cut, conditional on the worker experiencing a nominal base wage reduction were both around 7 percent. While the frequency of base wage increases is much higher than wage cuts, the mean size of a base wage increase is very similar to the mean size of a base wage cut.

In Online Appendix, we show a set of additional results surrounding time dependence in base wage adjustments. Conditional on a job-stayer receiving a base wage change during a year, most receive only one change. Most firms change the base wages of their employees in the same month. Most job-stayers receive a base wage change one-year from their last wage change. Workers who receive a wage change off-cycle (in a different month from most workers within the firm) tend to get higher wage increases than those who receive a wage change oncycle. Collectively, at the firm-worker level, these results show strong evidence of staggered contracts (see Taylor (1979)). However, different firms adjust the base wages of most of their workers in different months. There is some monthly seasonality in the probability of a worker receiving a wage change with January, April, July and October being the months with most frequent adjustments. However, when aggregating the data to quarterly levels, there is little quarterly seasonality. Given these facts, we compute a measure of the average duration of a base wage increase for a worker assuming Calvo adjustment. This is a crude measure given the evidence of state dependence presented in Section 10. But, given that the

\footnotetext{
${ }^{18}$ To limit the effect of extreme outliers when computing mean wage changes, we winsorize both the top and bottom $1 \%$ of nominal wages and the top and bottom $1 \%$ of wage changes. We only do this when computing the size of wage changes conditional on a wage change occurring. This does not affect our frequency of wage change results in any way.

${ }^{19}$ It should be noted that our wage growth for job-stayers includes a combination of cohort, time and age effects. The presence of age effects implies that wage growth for job-stayers are higher than the wage growth for the economy as a whole. See Beraja et al. (2016) who make a similar point when comparing time series and panel data wage growth patterns in the CPS during the Great Recession.

${ }^{20}$ In the Appendix Table A2, we also report the skewness and kurtosis of the distribution.
} 
Figure 3: Probability of base wage adjustment by initial wage percentile, 2008-2016

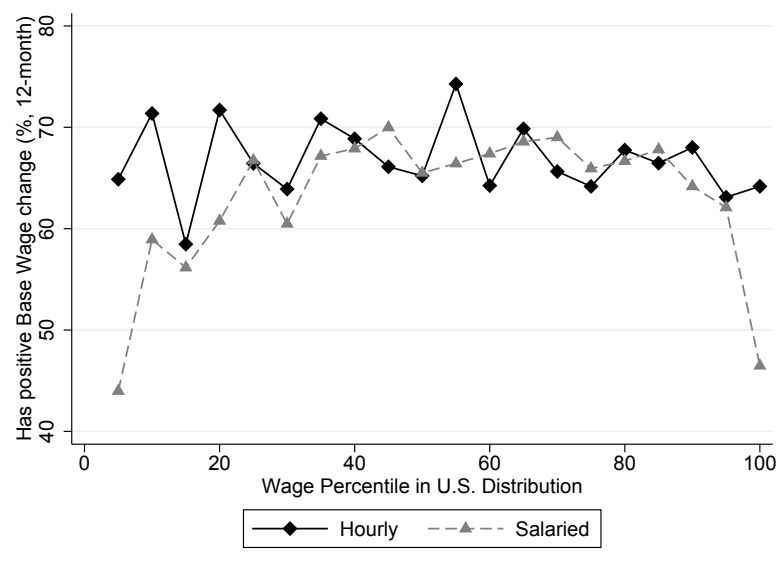

Panel A: Positive Changes

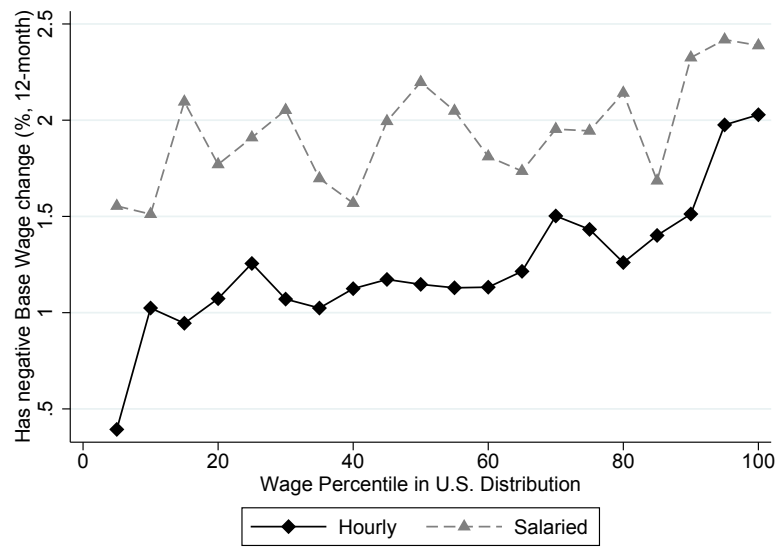

Panel B: Negative Changes

Notes: Figure shows the probability that a worker receives a year-over-year base wage increase (Panel A) or decrease (Panel B) by the worker's initial position in the national wage distribution for workers of her payment type (i.e. hourly or salaried). This plot covers the period 2008-2016, and plots the patterns separately for hourly workers (black solid lines with diamond markers) and salaried workers (gray dashed lines with triangle markers).

literature focuses on a measure of average duration in Calvo models of wage adjustments, we feel it is a useful statistic to use when comparing the nature of nominal wage adjustment across our different wage concepts. The results in Table 6 suggest the average duration of a nominal base wage for job-stayers is about 6.0 quarters.

\subsection{Heterogeneity in Base Wage Adjustment for Job-Stayers}

add in base wage adjustment heterogeneity by income...

\section{Nominal Base Wage Adjustments for Job-Changers}

The prior section focuses on nominal base wage adjustments for individual job-stayers. However, models in which most base wage adjustment originates from movements across firms or due to the arrival of outside offers, such as many labor search models (Menzio and Shi (2011); Cahuc et al. (2006)), may be better calibrated to moments measuring nominal wage adjustments for job-changers. In this section, we use the ADP data to provide such moments.

There is a large literature documenting that wages of job-changers are more pro-cyclical than those of job-stayers (see, for instance, Bils (1985); Haefke et al. (2013); Pissarides (2009); Martins et al. (2012) and Gertler et al. (2016)). These studies show that the wages of employees entering new jobs tend to move almost one-for-one with labor productivity, 
and that this high degree of pro-cyclicality persists even after controlling for detailed job characteristics; it does not appear to be completely due to pro-cyclical "job upgrading." Our paper contributes to this literature by using high quality administrative data on wages to measure not only the mean wage adjustment of job-changers, but also provides a number of moments of the distribution of wage changes for job-changers as a whole.

The analysis in this section uses our job-changer sample. When measuring wage adjustment for job-changers, three issues are worth noting. First, we stress that we are measuring wage changes for workers who move from one ADP firm to another ADP firm. An implicit assumption we make throughout the paper is that the patterns of nominal base wage adjustments for workers who migrate across ADP firms are similar to the patterns of nominal base wage adjustment for workers who migrate to and from non-ADP firms.

Second, the notion of a "firm" within the ADP dataset is a unit that contracts with ADP. Sometimes, multiple establishments within a firm contract separately with ADP or firms will spin off into multiple units each contracting separately with ADP. In this case, a movement from one establishment within a firm to another establishment within the same firm will look like a job-change. To account for such flows, we measure the percent of job-changers leaving a given firm in month $t$ and showing up at another ADP firm in month $t+1$ or month $t+2$. If more than twenty percent of job-changers leaving firm $i$ subsequently show up in firm $j$ with no intervening employment spell elsewhere between $t$ and $t+2$, we treat switches from $i$ to $j$ as within firm movements over this time period, and do not include them in our job-changer sample. In addition, if a worker's reported tenure does not reset after switching firms, we exclude that worker from the job-changer sample.

Finally, the choice of timing is more nuanced given the nature of our data. As with job-stayers, we can measure base wage changes for job-changers at one-month, one-quarter, and one-year frequencies. However, when we see a worker at firm $i$ in month $t$ and then see a worker at firm $j$ in month $t+12$, the worker may have multiple other jobs in the interim. Because we only measure labor market outcomes for ADP firms, if a worker disappears from our dataset for a short time but reappears later, we are not able to distinguish if the worker was not employed or whether the worker was employed but at a non-ADP firm. For many applications, such distinctions are not important. However, it is worth keeping such timing issues in mind when interpreting our wage adjustment measures for job-changers. ${ }^{21}$

Figure 4 plots the distribution of 12-month nominal base wage changes for a sample of job-changers. The patterns are strikingly different from the patterns in Figure 2. First,

\footnotetext{
${ }^{21}$ We restrict our analysis to include only those workers who switch between either hourly jobs or who switch between salaried jobs. We exclude those who switch between the two types of jobs. These switches across payment types are relatively rare, but generate large swings in base wages in almost all cases.
} 
Figure 4: 12-Month Base Wage Change Distribution for Job-Changers

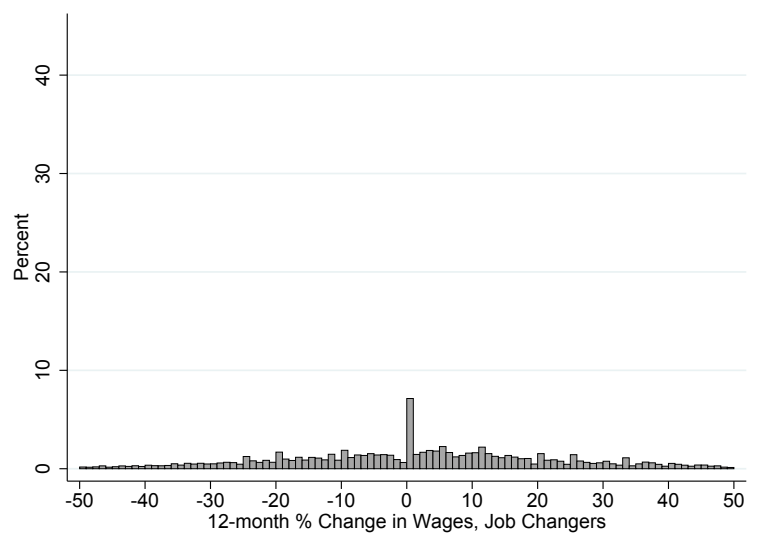

Panel A: Hourly-to-Hourly Changers

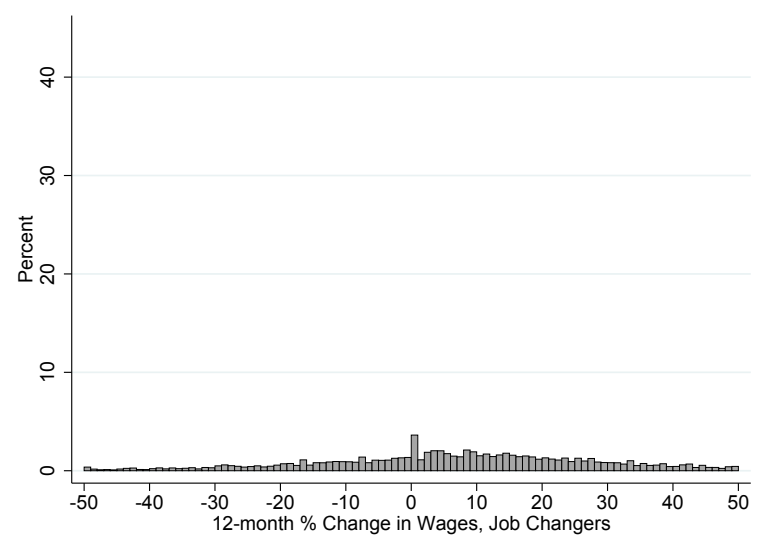

Panel B: Salaried Changers

Notes: Figure shows the 12 month change in nominal base wages for workers in our job-changer sample. We include all data from 2008-2016. See text for additional details.

essentially all workers receive a base wage change over a given year if they change jobs. Only about 6.5 percent of hourly job-changers and 3.3 percent of salaried job-changers do not receive a year-over-year base wage change. Second, the propensity for a base wage cut is very high for job-changers with $39.2 \%$ of workers paid hourly and $31.2 \%$ of salaried workers receiving a base wage decline during a job-change. Finally, the distribution of base wage changes is more symmetric around zero. As seen from the figure, there are roughly as many small base wage increases (0-2 percent) as there are slightly larger base wage increases (24 percent). There is much more base wage adjustment for job-changers than there is for job-stayers.

Table 8 shows key statistics on the distribution of base wage changes for job-changers. Conditional on a job change and a base wage change, mean and median annual base wage growth was 8.0 and 4.6 percent accordingly. Base wage growth is much larger for job-changers than it is for job-stayers. As seen from Figure 4, there is a large amount of heterogeneity in base wage changes for job-changers. Job-changers whose nominal base wage increased over the year experienced, on average, a 26.1 percent increase. Job-changers whose nominal base wage fell over the year experienced, on average, a 18.5 percent wage cut. Moreover, the standard deviation of annual nominal base wage changes for job-changers is 29.3 percent almost five times larger than the standard deviation of annual nominal base wage changes for job-stayers. ${ }^{22}$

\footnotetext{
${ }^{22}$ The patterns of nominal wage changes of job-changers that we document using the ADP data are similar to the patterns found using French data in the 1990s as documented in Postel-Vinay and Robin (2002). Postel-Vinay and Robin (2002) document that about one-third of French workers experience a real wage
} 
Table 8: Nominal Base Wage Change Statistics, Pooled 2008-2016 Sample of Job-Changers

\begin{tabular}{lcc}
\hline \hline & Quarterly & Annual \\
\hline & & \\
Prob of Positive Change (\%) & 52.7 & 56.8 \\
Prob of Negative Change (\%) & 37.4 & 38.0 \\
& & \\
Mean Unconditional Change (\%) & 6.3 & 8.0 \\
Median Unconditional Change (\%) & 2.3 & 4.6 \\
S.D. of Unconditional Change (\%) & 25.9 & 29.3 \\
& & \\
Mean Conditional Change (\%) & 7.0 & 8.5 \\
Median Conditional Change (\%) & 5.0 & 6.0 \\
S.D. of Conditional Change (\%) & 27.2 & 30.1 \\
& & \\
Mean Change, Conditional on Positive (\%) & 23.5 & 26.1 \\
Median Change, Conditional on Positive (\%) & 16.7 & 18.5 \\
Mean Change, Conditional on Negative (\%) & -16.5 & -18.5 \\
Median Change, Conditional on Negative (\%) & -13.6 & -15.8 \\
\hline
\end{tabular}

Notes: Table shows moments of the wage change distribution for job-changers for different horizons. For this table, we use our job-changer sample and pool together hourly and salaried workers.

\section{Aggregate Nominal Wage Adjustments}

We now combine our measures of base wage adjustments for job-stayers and job-changers into an aggregate measure of nominal wage adjustments. ${ }^{23}$ This measure is appropriate for the study of movements of macro variables in models with no defined notion of a job-stayer of job-switcher, as is the case in canonical New Keynesian models such as Christiano et al. (2015), Christiano et al. (2005) and Schmitt-Grohé and Uribe (2012). The large sample of both job-stayers and job-changers at a high frequency is a unique feature of the ADP data which allows us to construct such a measure for the first time. The inclusion of job-switchers vastly reduces the degree of realized nominal wage rigidity in the economy, particular on the downside, relative to the job-stayer benchmark which has been measured in the literature to-date.

To construct an aggregate measure of nominal wage flexibility, one must combine the patterns of wage adjustment for job-stayers with the patterns for job-changers. Were the universe of workers available, this would be a relatively easy task. However, as noted above,

decline as they move from job-to-job with no intervening unemployment spell during a period of relatively low inflation.

${ }^{23} \mathrm{New}$ entrants to the labor market also provide another margin of potential nominal wage adjustment. We are unable to measure job entrants within the ADP data so we abstract from them in our analysis. 
we can only measure job-changers who migrate between one ADP firm and another ADP firm. Given that ADP only has information on a subset of US workers, most job-to-job flows involve a non-ADP firm.

To circumvent this problem, we use aggregate data on job-to-job flows published by the US Census Bureau using data from the Longitudinal Employer Household Dynamics (LEHD) database. ${ }^{24}$ Using matched employee-employer records, Census creates measures of quarterly job flows. In particular, we use the Census's Job-to-Job Flows Data (J2J) focusing on transitions between workers' main jobs. For any given worker in quarter $t$ whose main job is at firm $i$, the J2J data measure the probability that the worker's main job in quarter $t+1$ remained at firm $i$ (job-stayers), was at a different firm $j$ (job-changers), or that the worker was not employed in quarter $t+1$ (become non-employed). These three probabilities sum to 1 within each quarter. Using data from 2008 through 2016, the quarterly job staying rate averaged 88.7 percent, the quarterly job switching rate averaged 4.6 percent, and the quarterly transition rate to non-employment was 6.9 percent. At the time of writing, the Census has not yet released annual job-to-job flows. As a rough approximation, we construct annual job changing rates by multiplying the quarterly rates by 4 . Doing so implies that 18.5 percent of workers switch job annually. ${ }^{25}$ In order to aggregate our job-staying and job-changing results, we weight our job-changing data by the fraction of job-changers in the LEHD data relative to one minus the fraction of job-changers. For quarterly data, we ensure that job-changers are weighted so that they represent 4.8 percent of workers $(0.046 /(1-0.046))$ on average. For annual data, we ensure that job-changers are weighted so that they represent 22.7 percent of workers $(0.185 /(1-0.185))$.

Table 9 shows statistics for the aggregate nominal base wage change distribution combining data from both job-stayers and job-changers. Column 1 of the table shows quarterly statistics on aggregate base wage changes while column 2 shows similar annual statistics. The table shows that there is much more aggregate nominal base wage flexibility than one would conclude from looking at job-stayers alone. Over the entire sample period, roughly 71.3 percent of workers receive a nominal wage change. Of those, nearly 9 percent received nominal base wage declines, compared with 2 percent of job-stayers. While nominal base wage declines are still rare in the aggregate relative to nominal wage increases, including data on job-changers quadruples the amount of nominal base wage cuts relative to looking

\footnotetext{
${ }^{24}$ See https://lehd.ces.census.gov/data/j2j_beta.html, accessed June 30, 2018. We focus on the job-to-job flows at the quarterly frequency allowing for at most short unemployment spells between the job transitions.

${ }^{25}$ This approximation is consistent with aggregate data on job tenure. Hyatt and Spletzer (2016) use tenure supplements to the CPS and matched employer-employee data from the LEHD to document that roughly 20-25 percent of workers have tenure less than a year during the 2008-2014 period.
} 
Table 9: Moments of Aggregate Wage Change Distribution Combining Job-Stayers and JobChangers, Pooled 2008-2016

\begin{tabular}{lcc}
\hline \hline & & \\
& Quarterly & Annual \\
\hline & & \\
Probability of Positive Wage Change (\%) & 20.6 & 62.7 \\
Probability of Negative Wage Change (\%) & 3.2 & 8.7 \\
& & \\
Mean Unconditional Change (\%) & 1.2 & 4.4 \\
Median Unconditional Change (\%) & 0.0 & 2.5 \\
S.D. of Unconditional Change (\%) & 6.7 & 12.0 \\
& & \\
Mean Conditional Change (\%) & 5.3 & 6.2 \\
Median Conditional Change (\%) & 3.1 & 3.5 \\
S.D. of Conditional Change (\%) & 13.1 & 13.9 \\
\hline \hline
\end{tabular}

Notes: Table shows aggregate moments of base wage adjustment at different horizons combining data on both job-stayers and job-changers during the 2008-2016 period. For this table, we pool together both hourly and salaried workers. We use our employee sample for this analysis. See text for additional discussion of our job-changer sample.

at only job-stayers. Moreover, the standard deviation of base wage growth - both unconditionally and conditional on a wage change - is over twice as large in the aggregate as amongst job-stayers. For example, unconditionally, the standard deviation of nominal base wage growth in the aggregate is 12 percent while the standard deviation of base wage growth for job-stayers is about 6 percent.

Overall, the inclusion of job-changers in our measures of wage rigidity greatly increases realized flexibility in the economy. Although job-stayer wage rigidity may have a complicated equilibrium relationship with the decision to switch jobs, the evidence presented here has important consequences for the quantitative predictions of existing macro models. The excessive rigidity inferred by simply considering base wage adjustment for job-stayers will lead New Keynesians to overstate the pass-through of monetary policy to real quantities. Similarly, those studying the extent to which downward nominal rigidities could contribute to sluggish wage growth should be aware that roughly $9 \%$ of workers received an annual base wage cut and $21 \%$ received an annual modified earnings cut from the period 2008-2016. Even if base wages for job-stayers appear exceptionally downwardly rigid, aggregate wage levels have not been as inflexible over the past ten years, owing to the high churn of employment in the US economy and adjustments to other forms of compensation. 


\section{The Cyclicality of New Hire Base Wages}

As Pissarides (2009) makes clear, the flexibility of new hire wages is the key determinant of aggregate employment fluctuations in many models. As a result, a large literature dating back to Bils (1985) has established that job-changers' wages are more cyclical than those of job-stayers, which we confirm with the ADP data above. However, the cyclicality of new hire wages does not necessarily map directly into new hire wage rigidity. This is principally due to selection: if lower quality workers are more likely to be displaced during a recession, wages of new hires may look lower in recessions than in booms, even if the wage per efficiency unit of labor were perfectly rigid. Similarly, if firms hire higher quality workers in a recession, this could potentially mask the cyclicality of a given new hire's wages. This idea has been well established in the literature by, for instance, Solon et al. (1994, 1997), and more recently by Gertler et al. (2016) who show that much of the cyclicality of new hire wages may be explained by pro-cyclical match quality.

A cleaner measure of new hire wage rigidity would compare the evolution of wages of new hires within a firm with that of similar incumbent workers within the same firm. If new hire wages are more flexible than incumbent workers, then job-changer wages should be lower than the wages of job-stayers who work in the same job during downturns, and higher (modulo tenure effects) in booms. By conditioning on worker type, this measure reduces the influence of selection on new hire wage cyclicality, thereby better reflecting traditional notions of wage rigidity.

Controlling for selection in this way is challenging in practice. We proceed by constructing a matching estimator, which compares the year-over-year base wage adjustment of jobchangers to a matched job-stayer, who is of a similar age and initial wage level (a proxy of the worker's unobserved type) and works at the changer's destination firm. Throughout this analysis, we focus on our job-changer sample. Define $w_{j, t-1}^{i}$ as the base wage (measured in nominal dollars per hour) of worker $i$ who works at firm $j$ in year $t-1$. As above, we assume that salaried employees work 40 hours per week when making their hourly base wage measure. We treat this as a measure of a worker's quality in $t-1$. Define $a_{t-1}^{i}$ as individual $i$ 's 5-year age bin (e.g. 21-25, 26-30, etc.) in year $t-1$. Finally, define $p_{t-1}^{i}$ to be individual $i$ 's percentile within the national wage distribution in year $t-1$.

To construct our matching estimator, we begin by examining the base wage adjustment of job-stayers. Denote by $\mathcal{I}_{t}^{j}(p, a)$ the set of workers who work for firm $j$ continuously between years $t-1$ and $t$, and who lie in wage percentile $p$ and age group $a$ in $t-1$ :

$$
\mathcal{I}_{t}^{j}(p, a)=\left\{i:\left(p_{t-1}^{i}=p\right) \cap\left(a_{t-1}^{i}=a\right) \cap(i \text { works for } j \text { in } t-1 \text { and } t)\right\}
$$


Denote by $N_{t}^{j}(p, a)$ the size of this set: i.e. the number of job-stayers at firm $j$ at percentile $p$ and age $a$. For every combination of wage percentile and age bin within a firm, we construct the mean wage change for job-stayers: ${ }^{26}$

$$
\Delta_{t}^{j}(p, a)=\frac{\sum_{i \in \mathcal{I}_{t}^{j}}\left(\ln w_{j, t}^{i}-\ln w_{j, t-1}^{i}\right)}{N_{t}^{j}(p, a)}
$$

The goal is to compare this $\Delta_{t}^{j}(p, a)$ to the wage changes of similar job-changers into firm $j$. We therefore turn to our job-changer sample and construct the 12-month base wage change for every switcher in our sample as they move from firm $j$ to $j^{\prime}$, exactly as in section 6 . Denote the change of switcher $i$ as $d w_{i}^{c}$. Then we compare each job-changer $i$ moving to firm $j^{\prime}$ with a matched job-stayer at that same firm with the same initial wage percentile and age group; that is we compare $d w_{i}^{c}$ to $\Delta_{t}^{j}\left(p_{t-1}^{i}, a_{t-1}^{i}\right)$.

Figure 5 plots the results of this matching exercise. Panel A plots the mean wage changes of job-changers (black lines) and their matched job-stayers (gray lines) throughout the base wage distribution. The solid lines with diamond markers show the patterns for the recovery period from 2012-2016, while the dashed lines with circle markers present the mean wage changes in the recession period of 2008-2010. ${ }^{27}$ The plot shows a negative relationship between mean wage changes and initial wage percentile for both changers and stayers, in part reflecting life cycle effects. ${ }^{28}$ However, this relationship is less pronounced during the recession. In the recovery period, an individual at the median of the national income distribution could expect a $5.5 \%$ increase in wages on average, but this fell to $3.5 \%$ during the recession, which mirrors the procyclicality of new hire wages documented in the literature.

One can also see from Panel A that job-changers' wages evolve similarly to those of their matched job-stayer counterparts: the black lines trace the gray lines very closely. Panel B plots the difference between changers' and matched stayers' year-over-year wage changes for the recession (dashed line) and recovery (solid line) periods. For the majority of the wage distribution, the recovery line is above the recession line, indicating that job-changers had lower wage growth relative to similar job-stayers in the recession than in the recovery. This suggests that new hire wages are more flexible than that of incumbent workers. However, the

\footnotetext{
${ }^{26}$ To maximize power, we use the full ADP data for this exercise, rather than any of our subsamples.

${ }^{27}$ We exclude the highest and lowest ventiles from the plot, because bottom earners (bottom five percent of the wage distribution) are constrained by institutional details such as the minimum wage, and the distribution of top earners' income (top five percent of wage distribution) is quite disperse, reducing the reliability of our match based on wage percentiles.

${ }^{28}$ Although the matching between job-changers and stayers is done with age, the wage percentiles are calculated using the national distribution. Thus Panel A includes life cycle effects in the mean wage change. In addition, we match based on percentiles, but collapse to mean changes by ventile for legibility.
} 
Figure 5: Job-Changers' Wage Changes Compared with Matched Job-Stayers, by Period

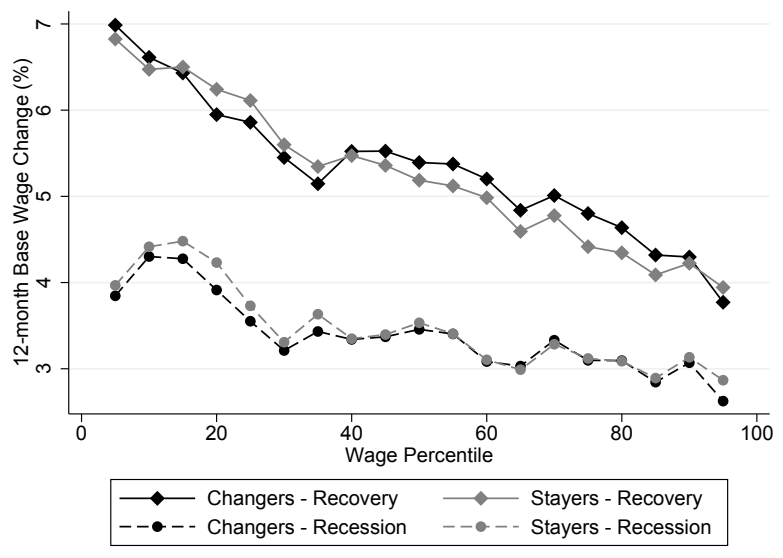

Panel A: Changers And Stayers SEPARATELY

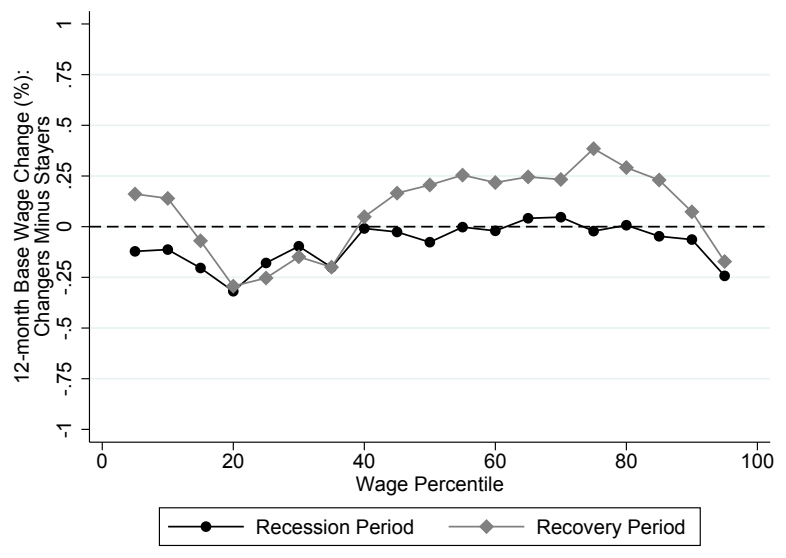

Panel B: Changers minus Stayers

Notes: Figure plots results of our matching exercise detailed in the text. Job-changers are matched to job-stayers in the same destination firm, at the same initial wage percentile, and same age. We then plot the mean 12 month wage changes of both changers and their matched stayer by wage ventile (Panel A), and the mean difference between changer and matched stayer (Panel B).

size of this difference is quite small in magnitude: on average, changers experienced a wage increase relative to their matched job-stayers which was 22 basis points lower in the recession than in the recovery. Indeed, if we regress, at the individual changer level, the gap between changers' wage growth and their matched stayer's wage growth $\left(\Delta_{t}^{j}\left(p_{t-1}^{i}, a_{t-1}^{i}\right)-d w_{i}^{c}\right)$ on a recession indicator controlling for individual age, initial wage percentile, industry, firm size, sex, and an indicator for being hourly, we find that the gap between changers and stayers becomes a statistically significant 19 basis points more negative in the recession. ${ }^{29}$ Given the individual standard deviation of this gap is 8 percentage points, and the mean gap is just 24 basis points over our whole sample, this constitutes a relatively small effect. For comparison, Gertler et al. (2016) find that a one percentage point increase in the aggregate unemployment rate is associated with a reduction of job-changer wage growth which is one percentage point larger than that of job-stayers. We find that the roughly 3 percentage points higher unemployment rate during the crisis was associated with a disproportionate reduction in job-changer wage growth of about 20 basis points, implying a semi-elasticity of 0.06, roughly one-twentieth of Gertler et al. (2016)'s exercise which does not control for compositional shifts of changers over the cycle.

Collectively, our new hire results yield a few key insights. First, we confirm above that job-changers have more cyclical wages than do job-stayers. Furthermore, after controlling

\footnotetext{
${ }^{29}$ We cluster standard errors at the destination firm level for this exercise; $p<0.001$.
} 
for selection as best we can, it remains true that job-changers' wages respond more in downturns than do job-stayers, suggesting some higher degree of new hire flexibility. However, this residual differential flexibility for job-changers appears quite small, suggesting that the majority of the increased cyclicality of job-changers can be explained through composition effects, as posited by Gertler et al. (2016). The results presented in this section complement those of Hazell and Taska (2018), who document that posted wages adjust about as frequently as do the wages of incumbent workers. New hire wages at the job level do not appear substantially more flexible than do those of job-stayers, suggesting that internal equity concerns may be important in wage setting.

\section{Including Bonuses in Measures of Nominal Wage Adjustments for Job-Stayers}

In this section, we gauge the importance of bonuses in providing an additional margin of flexibility for job-stayers. Bonuses have long been considered a potential source of additional wage cyclicality and earnings flexibility (Shin and Solon, 2007). For this analysis, we restrict our employee sample to include only non-commission workers who remain continuously employed with the same firm for 24 consecutive calendar months. The reason for excluding commission workers is that it is hard to isolate bonuses separately from other frequent irregular payments for such workers. The 24 consecutive calendar month restriction is necessitated by the fact that bonuses accrue annually. Given that our data starts mid-year through 2008, our bonus sample pools together workers for all two year periods between 2009 and 2016. During our sample period, 44.5 percent of non-commission job-stayers received no bonus both in year $t$ and year $t+1$ while 32.4 percent of non-commission job-stayers received a bonus in both year $t$ and $t+1$. The remaining 23.1 percent of workers received a bonus in only one of the two years.

To assess how bonus flexibility affects the frequency of nominal wage adjustment, our bonus and our base wage measures must be in the same units. We therefore define a measure of "modified monthly base earnings," which isolates fluctuations in a worker's base pay which arise from changes in wages rather than hours. Since salaried workers have no meaningful hours adjustments, modified monthly base earnings for salaried workers is simply their monthly base earnings (their base wage times the number of pay periods per month). However, modified monthly base earnings for hourly workers is their monthly base wage times the average monthly hours worked over the relevant two year period. Specifically, when we explore changes in nominal wage adjustments inclusive of bonuses between year $t$ and $t+1$, 
average monthly hours worked for hourly workers is simply the total annual hours worked in both years $t$ and $t+1$ divided by 24. By fixing number of hours for hourly workers, we ensure that all the movements in modified base monthly earnings is coming from changes in the base wage; it is in this sense that the earnings are "modified". Given that bonuses are measured annually, we then make a measure of "modified annual base earnings" by summing the monthly modified earnings for each worker over a 12 calendar month period.

Our key variable of interest is "modified annual total earnings" which is computed as the sum of modified annual base earnings plus annual bonuses. It is worth stressing that our modified annual total earnings variable differs from annualized total earnings in two ways. First, the measure includes only earnings from base wages and bonuses. It excludes any earnings from overtime premiums and other small infrequent payments. Second, it normalizes the hours for hourly workers to be the average annual hours worked over a given two year period. The benefit of this is that any movement in this earnings measure across the two years is attributed to a change in base wages or a change in bonuses.

Panel A of Figure 6 shows the 12 month change in modified annual base earnings as defined above for non-commission workers who remain continuously employed on the same job for two calendar years. Not surprisingly, this figure is very similar to those presented in 2. Both only measure variation in base wages over time. The only difference between the two figures results from selection on non-commission workers and time aggregation. Most of the difference stems from time aggregation. Given that Panel A of Figure 6 measures nominal wage adjustments between all of $t-1$ and all of $t$, wage changes that occur prior to December of $t-1$ will show up as an additional amount of nominal wage adjustment in the right hand figure. As a result, the variance of changes is slightly higher for annual modified base earnings relative to 12 -month changes in base wages. However, even despite the time aggregation issues, the distribution of changes in modified base earnings include essentially no nominal wage cuts.

Panel B of Figure 6 presents the annual change in annual modified earnings (inclusive of bonuses) for all non-commission workers in our sample. Notice relative to Panel A, the change in annual modified earnings (inclusive of bonuses) is much more dispersed. While only 2.9 percent of workers received a modified base earnings decline over a 12 month period, 15.7 percent of workers saw reduced annual nominal wages inclusive of bonuses. Additionally, accounting for bonuses also increases the standard-deviation of nominal wage changes from 4.6 percent to 7.7 percent.

Bonuses provide firms with an additional margin of wage adjustment for their employees. As highlighted above, at the worker level, bonuses are not persistent. The amount of a worker's bonus received in year $t$ is not predictive of the amount of the worker's bonus 
Figure 6: Annual Changes in Modified Base Earnings and Modified Annual Earnings: 24month Job-Stayers, Excluding Commission Workers

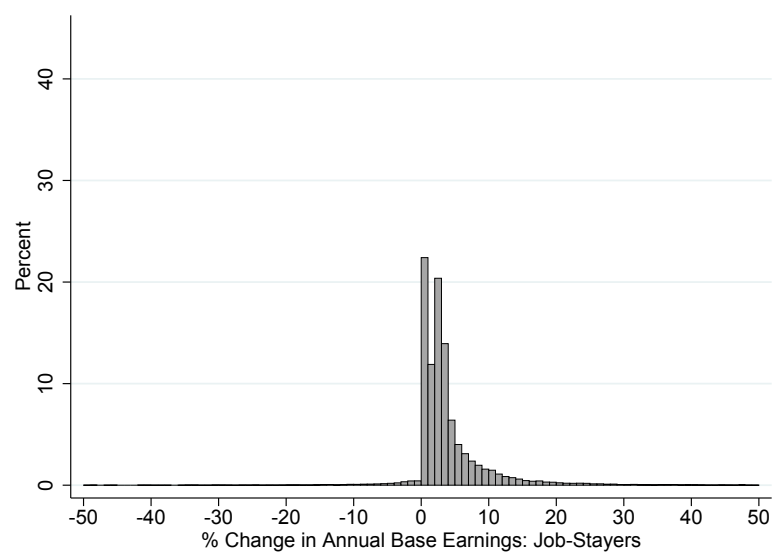

Panel A: Modified Base Earnings

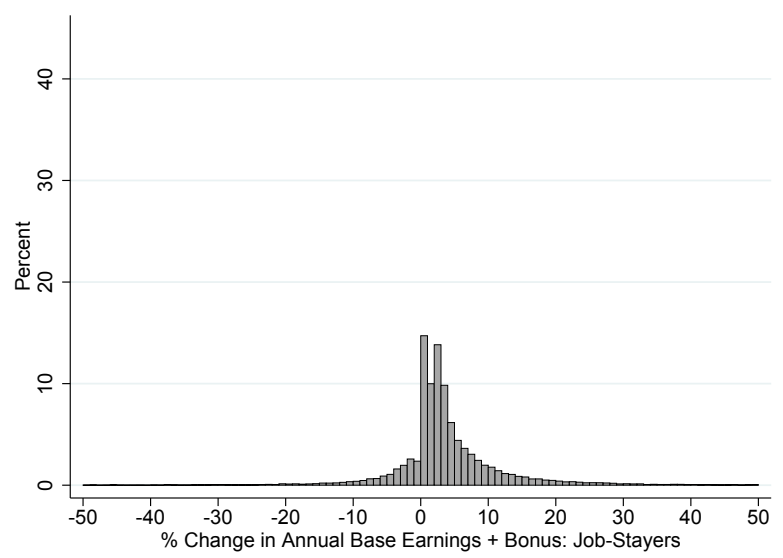

Panel B: Modified Annual Earnings

Notes: Figure plots the distribution of year-over-year changes in base wage (Panel A) and modified base earnings (Panel A) and modified annual earnings (Panel B). Modified base earnings are base earnings holding fixed hours for hourly workers. Modified annual earnings is modified base earnings plus annual bonus payments. Figure restricts attention to a sample of 24-month job-stayers excluding commission workers, between 2009 and 2016.

received in year $t+1$. Given that, while bonuses provide some flexibility to a worker's spot wage in a given year they are less important when thinking about the user cost of hiring a worker. But, there is no doubt that bonuses are important when thinking about the volatility of a worker's earnings from year to year. It is also worth stressing that the results in Figure 6 are consistent with contemporaneous work by Kurmann and McEntarfer (2018) and Jardim et al. (2019) who use data from the US Longitudinal Employer Household Dynamics (LEHD) survey and Washington State Unemployment Insurance Records to examine nominal annual earnings-per-hour adjustments for a sample of job-stayers who reside in Washington state. ${ }^{30}$ Both Kurmann and McEntarfer (2018) and Jardim et al. (2019) find that roughly 20 percent of workers receive a decline in nominal earnings per hour during a given year. While their results are not directly comparable to ours because they are focused only on residents of Washington state and also include overtime premiums and commissions in their earnings measure along with base wages and bonuses, it is encouraging that our annual variation in annual modified earnings matches closely their measure of annual variation in earnings per hour. What distinguishes our broader results from theirs is our ability to highlight how much of the variation is coming from base earnings verses bonuses. As highlighted throughout, such distinctions are important for many potential applications.

\footnotetext{
${ }^{30}$ They focus their sample on residents of Washington state because Washington requires employers to report the hours workerd of their employees as part of their Unemployment Insurance program.
} 
Figure 7: Modified Annual Earnings Fluctuations by Base Wage Quartile, 2-Year Sample of Job-Stayers Excluding Commission Workers, 2008-2016

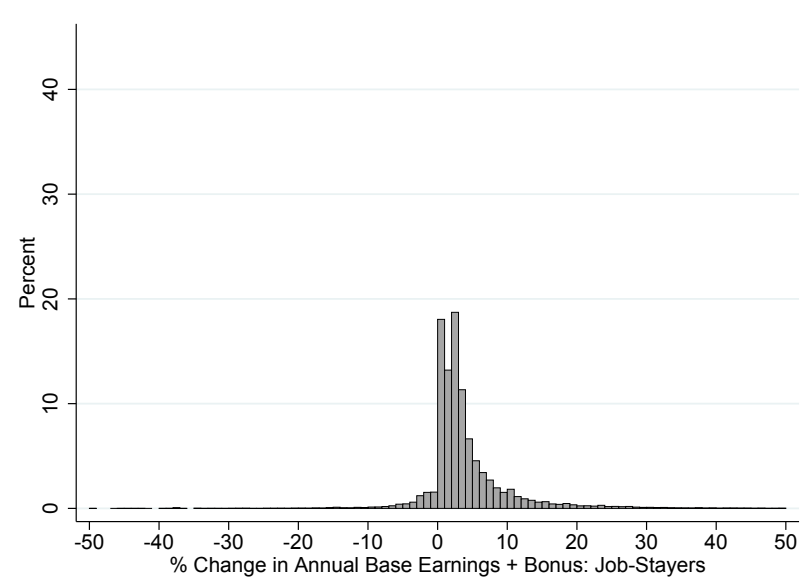

Panel A: Base + Bonus Changes: BotTom Quartile Wages

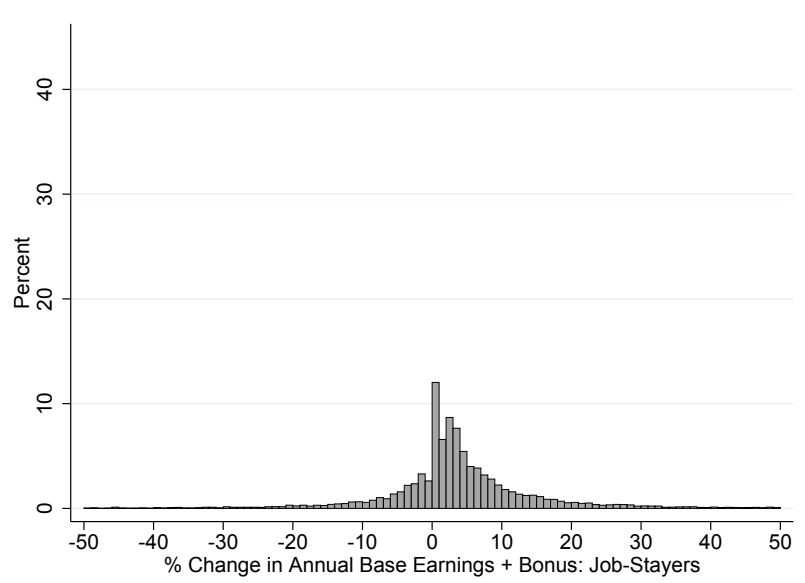

Panel B: Base + Bonus Changes: Top Quartile Wages

If bonuses do provide firms with additional flexibility in adjusting the nominal wages of their workers, they only do so for higher income workers. Figure 7 presents the distribution annual changes in modified base earnings plus bonuses (modified annual earnings) for two groups of workers: those in the bottom quartile of the base wage distribution (left panel) and those in the top quartile of the base wage distribution (right panel). For most low-wage workers, bonuses are trivial share of income. As a result, accounting for bonuses has little effect on low-wage workers' nominal wage adjustments, leading them to hardly ever receive nominal wage cuts. However, for high-wage workers, bonuses provide a large amount of additional flexibility. Incorporating bonus adjustments results in 23.6 percent of workers in the top wage quartile experiencing a nominal wage cut during a year. This result is interesting given the fact that much of the displacement of workers at business cycle frequencies comes from the bottom of the wage distribution. It also contrasts with the results in Section 5 which highlights that the probability of base wage adjustments do not vary a worker's base wage. The results in Figure 7 suggest there are potential gains from modeling heterogeneity across workers in the extent to which bonuses are part of their compensation if bonuses are an important margin of adjustment within the model.

The first two columns of Table 10 summarizes results on the frequency of modified base earnings and modified annual earnings (inclusive of base and bonuses) for our sample of 2-year job-stayers. The third column of the table shows a measure of aggregate nominal wage adjustments inclusive of bonus income for job-stayers and accounting for the aggregate amount of job-changers. Specifically, we focus on annual modified earnings for job-stayers 
Table 10: Moments of the Annual Change Distribution Across Wage Notions, 2-year JobStayers, 2012-2016

\begin{tabular}{lccc}
\hline \hline & $\begin{array}{c}\text { Modified } \\
\text { Base } \\
\text { Earnings }\end{array}$ & $\begin{array}{c}\text { Modified } \\
\text { Annual } \\
\text { Earning }\end{array}$ & $\begin{array}{c}\text { Aggregate } \\
\text { Modified } \\
\text { Annual } \\
\text { Earnings }\end{array}$ \\
\hline Prob of Positive Change (\%) & 80.4 & 75.0 & 68.5 \\
Prob of Negative Change (\%) & 2.9 & 15.7 & 21.6 \\
& & & \\
Mean Unconditional Change (\%) & 3.7 & 4.0 & 5.2 \\
Median Unconditional Change (\%) & 2.7 & 2.7 & 2.8 \\
SD of Unconditional Change (\%) & 4.6 & 7.7 & 16.9 \\
& & & \\
Mean Conditional Change (\%) & 4.5 & 4.4 & 5.8 \\
Median Conditional Change (\%) & 3.0 & 3.0 & 3.3 \\
SD of Conditional Change (\%) & 4.7 & 7.9 & 18.6 \\
\hline \hline
\end{tabular}

Notes: Table plots key moments of the wage change distribution for the sample of two-year job-stayers. Each column presents the moments of the distribution of a separate notion of wage. Column 1 highlights modified base earnings for job stayers. Column 2 highlights modified annual earnings which combines base earnings and bonuses for job stayers. Column 3 highlights aggregated modified annual earnings which combines changes in modified annual earnings for job-stayers and changes in base wages for job-changers. 
(column 2) and combine that with annual base wage changes for job-changers with the jobchangers weighted accordingly using the aggregate job-to-job transition weights discussed above. ${ }^{31}$ In aggregate data, spot wages are more flexible both because of job-changers and because bonuses are moving around at annual frequencies. As seen from Column 3 , in the aggregate, 21.6 percent of all workers receive a nominal wage decline during a given year when accounting for job-changers and bonuses received by job-stayers.

We conclude this section by briefly discussing how accounting for fringe benefits affects the frequency of nominal wage adjustments. When exploring the importance of fringe benefits, we created an additional wage measure which was defined as modified annual earnings (inclusive of bonuses) plus the annual value of employer-provided health insurance and contributions to deferred compensation plans. Incorporating fringe benefits into our analysis does not substantively alter the frequency of annual changes either up or down. The probability of an increase in base earnings plus bonuses and fringe was about 78 percent. The comparable probability for the increase in base earnings plus bonuses (column 2 of Table 10) is 77 percent. Both the size of the increase and the standard deviation of the change are larger after including fringe benefits with the standard deviation increasing from $7.7 \%$ to $10.9 \%$. These patterns are consistent with benefits being a relatively constant fraction of a worker's earnings. As a worker's base earnings change, so too does their fringe benefits. Under this scenario, accounting for fringe does not alter the propensity for a worker to receive a wage change, but would scale up both the mean and the standard deviation of changes.

\section{State Dependence in Aggregate Nominal Wage Ad- justment}

In this section, we examine the extent to which aggregate wage adjustments move with aggregate and firm-specific conditions. Many macro models of wage adjustments assume a constant parameter for the probability that a worker receives a wage adjustment. Using a variety of methodologies, we highlight that the probability of a wage adjustment varies substantively with aggregate and firm level economic activity.

\footnotetext{
${ }^{31}$ We cannot include bonuses for job-changers, as we do not observe a full year of data for job-changers that join their jobs in months other than January.
} 


\subsection{Time Series Variation in the Nominal Wage Adjustments, Job-Stayers}

There are two principal reasons why one might observe state dependence in realized nominal wage changes for job-stayers. The first is if there is some explicit cost for firms to adjusting the wages of existing workers. Non-convex adjustment costs, or "menu costs," are commonly employed in New Keynesian models of price setting in order to match moments of the price data. The presence of fixed adjustment costs generates an inaction region whereby firms that are close to their optimal price in a frictionless economy do not adjust their prices until they move sufficiently far away from their optimal price. Thus, with a menu cost of adjusting prices, the state of the firm - its distance from the optimal pricing rule - is crucial in determining price adjustment decisions. As a result, price changes are infrequent, and relatively large when they occur. Although menu cost models of wage adjustments are rare,

principally due to challenges arising from wage bargaining, the intuition gained from the output pricing literature helps guide analysis of state dependence in wage setting.

A second reason for state dependence in nominal wage adjustments for job-stayers might arise in a framework with asymmetric rigidity. For instance, suppose that it is harder for firms to cut wages than to raise them, possibly due to concerns over morale or because of union pressure. Under this scenario, firms receiving a negative productivity shock would have a lower probability of being able to adjust wages to the desired level than firms receiving a positive productivity shock. This would imply that wages would then appear less flexible in downturns than in booms.

Figure 8 plots the time series of base wage adjustments for job-stayers using our employee sample pooling together both hourly and salaried workers. The top panel plots the extensive margin of base wage changes: the percent of all employees in month $t$ who have a different base wage from month $t-12$. As a reminder, our data starts in May 2008. That means the first observation in each of the panels in Figure 8 is for May 2009 and measures the fraction of job-stayers who received a base wage change between May 2008 and May 2009. The fact that our data spans the Great Recession allows us to explore business cycle variation in the extent of base wage adjustments.

As seen from the left panel of Figure 8, wage adjustments of job-stayers exhibits striking pro-cyclicality. Only about 55 percent of continuing wage workers received a year-over-year wage change during the depths of the recession. However, after the recession ended, during the 2012 to 2014 period, between 65 and 70 percent of workers received a wage change. As of the end of 2016, nearly 75 percent of all workers received a nominal base wage change. While most of the time series variation was between the recession and non-recessionary periods, 
Figure 8: Time Series of Nominal Base Wage Adjustments, Job-Stayers

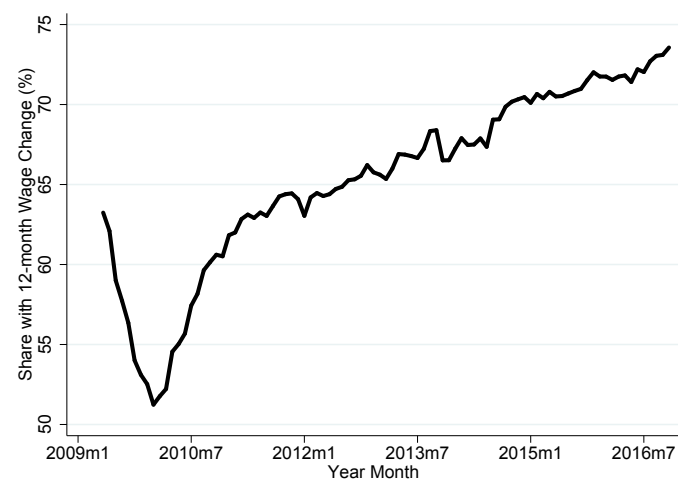

Panel A: Has Wage Change

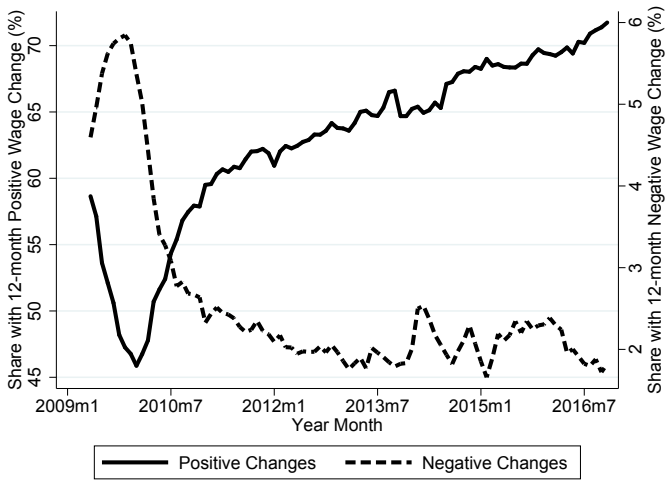

Panel B: Has Wage Change: Pos. Vs NeG.

Notes: Figure plots the propensity to receive a 12-month base wage change over time for our employee sample of job-stayers between May 2009 and December 2016. The data are weighted to match the firm size $\times$ industry mix found in the BDS.

there is still a trend upwards in the share of workers receiving an annual base wage change between 2012 and 2016.

The right panel of Figure 8 separates the probability of a base wage change of jobstayers into the probability of a base wage increase (solid line - measured on the left axis) and the probability of a wage declines (dashed line - measured on the right axis). During the Great Recession, the propensity of base wage increases for job-stayers fall sharply and the propensity of base wage declines increases sharply. While nominal base wage cuts are exceedingly rare for job-stayers during non-recessionary periods, upwards of 6 percent of all continuing workers received a nominal base wage cut during late 2009 and early 2010.

Although not shown in the figure, the mean size of base wage changes, conditional on a wage change occurring, is also highly procyclical. During the Great Recession, the mean size of a nominal base wage change for those receiving a base wage change was about 5 percent. The corresponding number as of 2016 was 6.5 percent. Putting the above results together, within-firm nominal base wage growth for job-stayers is highly pro-cyclical. For employees who remain with the firm, both the probability and size of nominal base wage raises are increasing in business cycle conditions. There is a large literature on the cyclicality of aggregate wages. ${ }^{32}$ Our results show that for a given worker on the job, nominal base wage changes are also strongly pro-cyclical.

The first two columns of Table 11 summarizes the business cycle differences in nominal

\footnotetext{
${ }^{32}$ See, for example, Solon et al. (1994), Gertler et al. (2016) and the recent survey by Basu and House (2016).
} 
base wage adjustments for job-stayers. We separate the sample into two periods: a period representing the depths of the Great Recession (May 2009-December 2010) and a period well into the recovery (January 2012 - December 2016). Consistent with the results in Figure 8, nominal wage cuts were more prevalent during the recession than during the recovery period. Base wages are less downwardly rigid during the Great Recession. 4 percent of job-stayers overall and 6 percent of salaried job-stayrs received a base wage decline during the Great Recession. While base wages were more downwardly flexible during the Great Recession for job-stayers, the fraction of workers receiving a zero nominal base wage change also increased for both salaried and hourly workers. Interestingly, the unconditional standard deviation of base wage changes fell slightly during the recession for all workers from 7.0 percent to 6.3 percent. In summary, overall nominal base wage adjustments fell during the Great Recession but downward adjustments increased.

Table 11: Summary of 12-Month Wage Change Distribution During and After the Great Recession, Job-Stayers and Job-Changers

\begin{tabular}{lccccc}
\hline \hline & \multicolumn{2}{c}{ Job-Stayers } & & \multicolumn{2}{c}{ Job-Changers } \\
\cline { 2 - 3 } \cline { 5 - 6 } & $2009-2010$ & $2012-2016$ & & $2009-2010$ & $2012-2016$ \\
\hline & & & & & \\
Prob of Negative Wage Change(\%) & 4.2 & 2.0 & & 44.0 & 36.4 \\
Prob of No Wage Change (\%) & 43.3 & 30.6 & & 5.5 & 5.5 \\
Prob of Positive Wage Change (\%) & 52.5 & 67.4 & & 50.5 & 58.1 \\
S.D. of Wage Change (\%) & 6.3 & 7.0 & & 31.4 & 28.9 \\
\hline \hline
\end{tabular}

Notes: Table shows the distribution of 12-month wage adjustment for job-stayers (columns 1 and 2) and job-changers (columns 3 and 4 ) over the cycle. The results are for a sample that pools together both hourly and salaried workers. For both job-changers and job-stayers, we show statistics for the period between May 2009 and December 2010 and the period between January 2012 through December 2016. The first two columns use our employee sample focusing on workers who remain continuously employed on their job for the entire twelve months between when the wage changes are measured. The last two columns use our job-changer sample and explore the 12 month change for workers who were employed at firm $i$ in $t$ and another firm $j$ in $t+12$. All data are weighted to match the firm size $\times$ industry mix found in the BDS.

Figure 9 shows time series trends in the probability of a nominal base wage increase (left panel) and a nominal base wage cut (right panel) for job-stayers by industry. During the Great Recession, manufacturing and construction were two of the hardest hit industries. Roughly 10 percent of construction workers and 8 percent of manufacturing workers who remained on their job received a year-over-year nominal base wage cut during 2009. The comparable numbers for retail and finance, insurance, and real estate (FIRE) were 6 and 3 percent, respectively. By 2012, continuing workers in all industries had a roughly 2 percent probability of receiving a nominal base wage cut. Note, the probability of a nominal base 
Figure 9: Time Series of Wage Changes by Industry, Job-Stayers

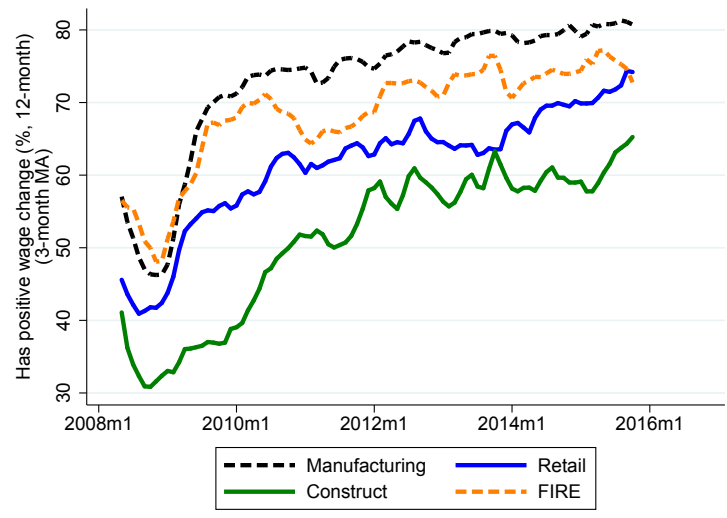

Panel A: Positive Change

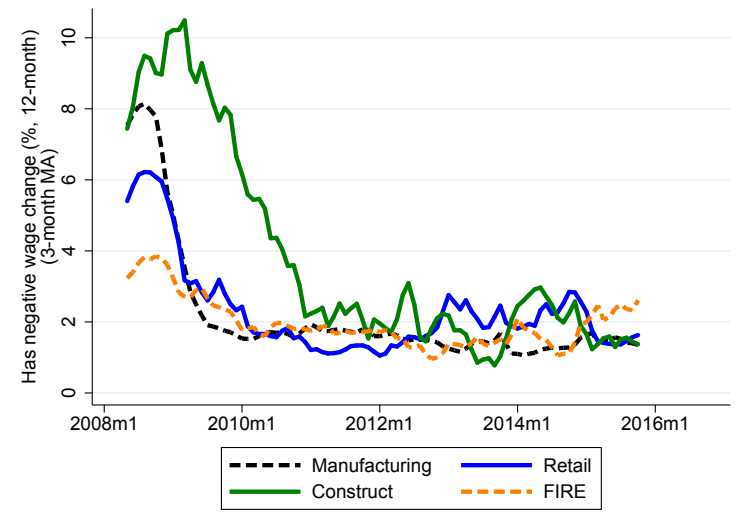

Panel B: Negative Change

Notes: Figure shows the propensity to receive a 12-month wage increase (Panel A) and decrease (Panel B) for job-stayers over the cycle, broken out for select broad industry groups. This figure makes use of our employee sample, weighted to match the firm size distribution found in the BDS within each industry. "FIRE" refers to Finance, Insurance, and Real Estate.

wage increase did not differ markedly across industries during the Great Recession. There are persistent level differences in the propensity of a nominal base wage increase across industries for job-stayers in all years. However, these differences remained relatively constant during the 2008-2016 period. These cross-industry patterns reinforce the time series patterns with respect to the state dependence of nominal base wage cuts of continuing workers. Not only were nominal base wage cuts more likely for job-stayers during the Great Recession, the propensity of nominal base wage cuts was highest in the industries hit hardest during the Great Recession. Firms in manufacturing and construction both were more likely to shed workers during the Great Recession and also were more likely to cut the base wages of the workers who remained with their firm.

The results in this subsection show that the composition of nominal base wage adjustment for job-stayers varies over the business cycle. Any model that assumes a constant hazard of base wage adjustments for job-stayers over the business cycle is at odds with the underlying wage setting data, and may lead to incorrect conclusions regarding the responsiveness of the economy to countercyclical monetary expansions.

\subsection{Time Series Variation in Aggregate Nominal Wage Adjust- ments}

As highlighted above, much of the flexibility in nominal base wage adjustments results from job-changers. The last two columns of Table 11 shows that the distribution of base wage 
adjustments for job-changers also varies over the business cycle. For the table, we report statistics of 12 month base wage changes for workers employed at firm $i$ in $t$ and then are subsequently employed at firm $j$ in $t+12$. During the Great Recession, 44 percent of workers who changed jobs received a nominal base wage decline. The comparable number during the recovery period was 36.4 percent. Like job-stayers, there was more downward nominal adjustment during the Great Recession. Some of the increased downward adjustment may be the result of selection. Workers who transition jobs during the Great Recession may be systematically different than the workers who transition during non-recessionary times. Below, when we explicitly look at new hire wages, we discuss such selection issues in greater depth. Putting the potential issue of selection aside, it is interesting that the differential patterns of adjustment over the business cycle are roughly similar for both job-changers and job-stayers.

Aggregate nominal base wage flexibility is a function of both the base wage adjustments for job-stayers and job-changers. However, in order to measure the cyclical nature of aggregate wage adjustments, we also need to know how the composition of job-stayers relative to job-switchers evolves at business cycle frequencies. We again use data from the Census's Job-to-Job Flow Data (J2J) made from the underlying data of the LEHD. Appendix Figure A14 shows the quarterly share of job-stayers and job-switchers in the J2J data between 2000 and 2015. The difference between the sum of the two lines and one is the fraction of workers who left employment for longer non-employment spells during the quarter. During the Great Recession, the quarterly job-switching rate fell to 4 percent while during the 20122016 period the quarterly job-switching rate returned to a pre-recession level of about 5.1 percent. Job-staying rates were roughly the mirror image of job-changing rates. As above, we construct annual job changing rates by multiplying the quarterly rates by 4 . Doing so implies that during the Great Recession 16 percent of workers switched jobs compared to roughly 20 percent during the recovery. When weighting the job-stayer and job-changer data, we ensure that 16 percent of workers were job-changers during the Great Recession and roughly 20 percent were job-changers during the recovery. Since job-changers receive nominal wage changes and cuts at a substantially higher rate than job-stayers, this composition effect therefore pushes towards lower aggregate flexibility during the recession, even if both changers and stayers observe less downward rigidity in recession periods.

The first two columns of Table 12 shows the cyclical patterns of aggregate nominal base wage adjustments combining data on both job-stayers and job-changers. ${ }^{33}$ As with Table 11, we break our sample into two periods: May 2009-December 2010 and January 2012December 2016. Focusing on the annual aggregate nominal base wage adjustments, 10.6

\footnotetext{
${ }^{33}$ We examine the cyclicality of bonus payments in Appendix Appendix F.2.
} 
Table 12: Key Moments of Aggregate Wage Change Distribution by Recession Period

\begin{tabular}{lcccc}
\hline \hline & \multicolumn{2}{c}{ 12-Month } & \multicolumn{2}{c}{ Modified } \\
& \multicolumn{2}{c}{ Base Wage } & \multicolumn{2}{c}{ Annual Earnings } \\
\hline & $\begin{array}{c}2008-2010 \\
(1)\end{array}$ & $\begin{array}{c}2012-2016 \\
\text { 2008-2010 }\end{array}$ & $\begin{array}{c}2012-2016 \\
(3)\end{array}$ & $(4)$ \\
\hline & & & & \\
Prob of Increase (\%) & 52.0 & 66.0 & 64.1 & 70.2 \\
Prob of Cut (\%) & 10.6 & 8.4 & 24.2 & 20.5 \\
Unconditional Mean Change (\%) & 3.0 & 5.0 & 4.1 & 5.7 \\
Unconditional Median Change (\%) & 1.3 & 2.6 & 2.3 & 3.0 \\
Unconditional Std Dev of Change (\%) & 12.1 & 12.4 & 17.4 & 16.6 \\
\hline \hline
\end{tabular}

Notes: Table reports key moments of the distribution of year-over-year changes in base wages (columns 1 and 2) modified annual earnings - base pay plus bonuses - (columns 3 and 4) for the aggregate economy including the increased adjustment of job-changers. The samples differ slightly between the two different notions of wages. For the base wage results, we restrict the job-stayer part of the sample to include those who remain continuously employed with the same firm for 12 consecutive months. For the modified annual earnings results, we restrict the job-stayer part of the sample to include those who remain with the same firm for two consecutive calendar years. In both cases, we use our results from the 12-month changes in base wages for job-changers. We then aggregate job-changers and job-stayers by upweighting job-changers in order to match the ratio of job-changers to job-stayers observed in the LBD. See text for additional details.

percent of workers in the aggregate economy received a nominal base wage decline during the Great Recession. The comparable number during non-recession times was 8.4 percent. While downward adjustments were slightly more common, upward adjustments were less common with only 52 percent of workers receiving a base wage increase during the 20092010 period. The unconditional standard deviation of base wage changes was slightly lower during the Great Recession.

Downward nominal wage rigidity has received a substantial attention as an explanation for why aggregate wages did not fall more during the Great Recession. The results above show that 10.6 percent of workers did receive nominal base wage cuts and another 37.4 percent received no nominal base wage increase. Much of the downward adjustments occur through job-changers. Moreover, both job-stayers and job-changers experienced more nominal base wage declines during the Great Recession than during the 2012-2016 recovery. However, the job-changing propensity also fell during the Great Recession reducing some of the aggregate flexibility in nominal base wage adjustments. The results in Table 12 provide a set of moments for researchers to calibrate models to assess whether the moments of the base wage adjustment distribution can lead to sufficient rigidities to explain why aggregate wage growth did not fall more during the 2008-2012 period. Again, we stress the importance of considering measures of aggregate base wage flexibility when assessing such claims: both the level and trend of rigidity implied by the job-stayer sample is substantially different than 
those found in the aggregate economy.

\subsection{The Cyclicality of Various Compensation Forms}

Throughout the paper, we have focused on base wages under the presumption that bonuses do not provide substantial flexibility in the allocative user cost of labor. In this section, we study the cyclicality of bonus and base wage adjustment separately. Unfortunately, our sample period contains only one aggregate recession. We therefore exploit cross-region variation in the severity of the Great Recession, and speed of the subsequent recovery, to maximize our estimating power. We focus on our sample of 12-month job-stayers, and collapse the ADP data down to the state-year level. We then regress various measures of adjustment the share of employees receiving a positive or negative wage change (measured December over December), the share of workers receiving a bonus, the mean share of workers' income accounted for by bonuses, and the log of the mean bonus payment in a given year - on the year-over-year change in the average unemployment rates prevailing in a given state-year. ${ }^{34}$ Specifically we estimate regressions of the form

$$
y_{s t}=\beta \Delta u_{s t}+\epsilon_{s t}
$$

where $y_{s t}$ is one of our measures of wage or bonus adjustment in state $s$ in year $t$, and $\Delta u_{s t}$ is the change between period $t-1$ and $t$ of the unemployment rate in state $s$.

Table 13: Cyclicality of Various Forms of Compensation - State level regressions, 2009-2016

\begin{tabular}{lccccc}
\hline \hline & \% With Pos. & \% With Neg. & \% Receiving & Share in & Log Mean \\
Wage Change & Wage Change & Bonus & Bonus & Bonus \\
& $(1)$ & $(2)$ & $(3)$ & $(4)$ & $(5)$ \\
\hline$\Delta$ Unemployment Rate (\%) & $-3.796^{* * *}$ & $0.606^{* * *}$ & -0.050 & -0.020 & -0.073 \\
& $(0.421)$ & $(0.130)$ & $(0.542)$ & $(0.075)$ & $(0.061)$ \\
& & & & & 300 \\
Observations & 300 & 300 & 300 & 300 & 300 \\
Mean of Dep. Var. & 87.424 & 2.230 & 39.148 & 3.151 & 8.433 \\
S.D. of Dep. Var. & 5.464 & 1.606 & 5.372 & 0.745 & 0.629 \\
\hline \hline
\end{tabular}

Estimates of $\beta$ are presented in Table 13. The table shows that states with a one percentage point larger increase in the unemployment rate in a state is associated with approx-

\footnotetext{
${ }^{34}$ One may be concerned that bonuses are not determined by the state-level performance of the firm, but rather the firm's national performance. To test this, in unreported results, we estimate aggregate time series regressions using the aggregate unemployment rate as the measure of cyclicality. The results are noisier as a result of the short time series, but are qualitatively similar.
} 
imately XXX percentage points fewer nominal base wage increases, and XXX percentage points more nominal base wage decreases. These changes are both statistically and economically meaningful. In contrast, however, bonuses exhibit no statistically-significant cyclical pattern, whether "bonuses" are measured as the percent of a state's population receiving a bonus, the mean share of compensation being granted in bonuses, or the natural logarithm of the mean bonus earnings. ${ }^{35}$

To some degree this result should not be surprising. Many optimal contracting models would suggest that incentive pay, such as bonuses, should seek to filter out fluctuations in performance driven by factors outside of the control of the economic agent in question, such as the aggregate state of the economy.

\subsection{Within Firm Variation in Nominal Wage Adjustments}

To further shed light on the extent to which nominal wage adjustments respond to firmlevel shocks, we explore patterns in nominal wage adjustments by growing and contracting firms. To do so, we consider state dependence at the firm level by comparing moments of the wage change distributions for firms with differing levels of employment growth. We view this analysis as being a reduced form combination two potential effects. First, firms who experience negative employment growth are more likely to have received a negative firm-level shock. Firms receiving negative shocks are likely to adjust their labor inputs on multiple margins. As a result, firms experiencing negative employment growth may also be more likely to cut the wages of their existing workers and be less likely to give their existing workers a wage increase. Second, there may be a trade-off between adjusting wages and adjusting employment. For example, a financial-constrained firm receiving a negative cash flow shock may choose to cut wages or layoff workers in order to reduce their labor costs. Such a trade-off could in theory result in a negative relationship between firm employment growth and firm propensity to cut nominal wages.

Figure 10 plots the propensity for a firm to increase their workers nominal base wages (left panel) and the propensity for a firm to cut their workers' nominal base wages (right panel) as a function of observed firm size growth. To make this figure, we use our firm-level sample. All firm-level changes are at the annual level. As a result, the x-axis is the observed change in firm employment between months $t-12$ and $t$, while the y-axis is the share of the firm's workers which had their wages adjusted (up or down) over the same window. Each panel has two lines, reflecting LOWESS smoothed regression lines. The darker line restricts

\footnotetext{
${ }^{35}$ In unreported results, we also find no systematic cyclical pattern in the dollar-weighted share of pay in bonuses, or in the mean year-over-year bonus changes. As a result, the cyclicality of base plus bonus pay is less than that of base earnings.
} 
Figure 10: Probability of Wage Changes by Firm Growth Status

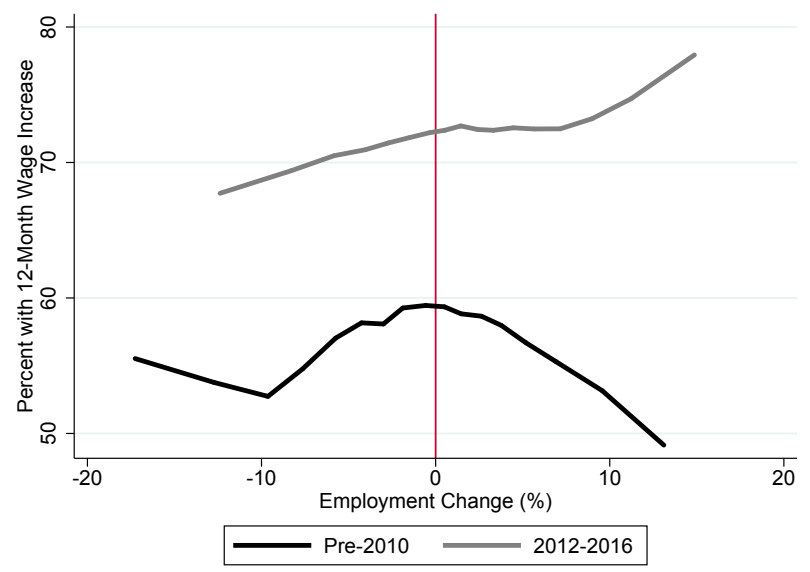

Panel A: Pr $\{$ Wage InCREase $\}$

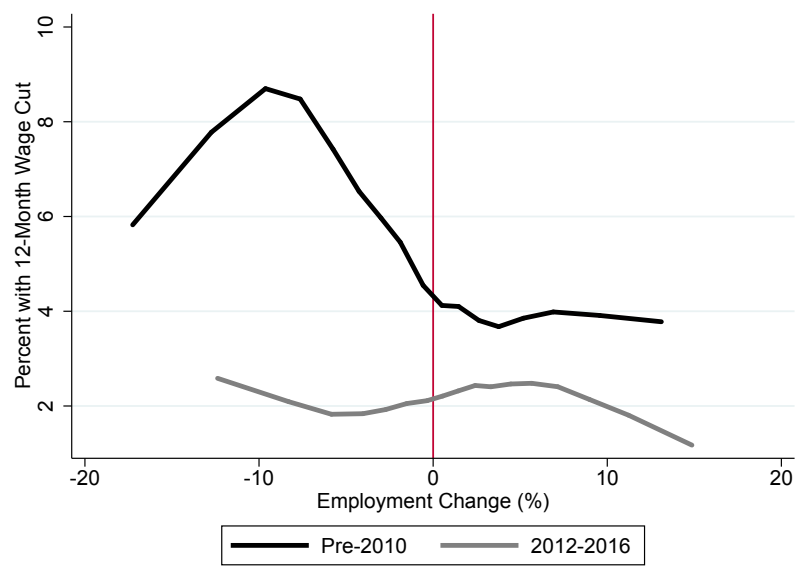

Panel A: Pr Whage Decrease $\}$

Note: Figure plots Locally-Weighted Scatterplot Smoothing (LOWESS) estimates of the relationship between the probability that a worker receives a wage increase (Panel A) or decrease (Panel B) and the firm's backward-looking year-over-year growth rate. The black line plots the patterns for the recession period of May 2009 through December 2010, while the gray line shows the conditional expectation function for the recover period, defined as January 2012 through December 2016. Our firm sample is used to construct this figure, and weighted to match the BDS' firm size $\times$ industry mix. Firm size is calculated after firm growth is taken into account.

our firm samples only to firm behavior during the Great Recession (2009-2010) while the lighter line restricts the sample to firm behavior during the recovery (2012-2016).

While not overly surprising, firms that grew were slightly more likely than firms that shrank to increase their workers wages during the 2012-2016. Specifically, firms that grew by 10 percent between 2012 and 2016 increased about 73 percent of their workers wages while firms that contracted by 10 percent during that period increased only about 68 percent of their workers wages. What is more surprising, however, is that during the Great Recession there was no systematic relationship between firm size growth and the propensity to rise workers wages. Across all firms, the propensity to raise wages was systematically lower during the Great Recession regardless of firm size growth.

During the Great Recession, however, contracting firms were much more likely to cut the nominal wages of their workers compared to firms that were stagnant or growing. Firms, whose employment fell by 10 percent over the year during the Great Recession, cut roughly 8 percent of their worker's wages. However, growing firms cut only 4 percent of their worker's wages. The propensity to cut wages again appears highly state dependent. The right panel of Figure 10 also shows another interesting fact. During non-recession times, there is no systematic relationship between firm size growth and the propensity to cut a worker's wage. Contracting firms in 2012-2016 were no more likely to cut nominal wages than growing 
firms. Moreover, growing firms during the Great Recession were much more likely to cut the nominal wages of their workers than growing firms during the recovery. This pattern would be consistent with aggregate conditions during the Great Recession being such that it is easier for any firm to cut the nominal wage of their workers when many other firms are also doing so.

The evidence presented in this section shows an important interaction between idiosyncratic and aggregate conditions for determining on-the-job wage adjustment patterns. This suggests that the value of workers' outside options are important for realized wage rigidity, a point which has been raised in, for instance, Christiano et al. (2015). The evidence here supports the hypothesis of state dependence in wage setting, which yields procyclical downward adjustment, and countercyclical upward adjustment. Further research is required to assess the impact of idiosyncratic firm shocks on aggregate wage movements over the cycle.

\section{Discussion}

Collectively, the results in the paper provide a set of high quality statistics on the wage change distribution for job-stayers, job-changers, and for the aggregate economy combining job-stayers and job-changers. We end the paper by highlighting how our estimates contrast with many of the existing estimates of nominal wage rigidity within the literature. As we highlight, our results differ in two important ways. First, we have administrative data which minimizes the importance of measurement error. Second, we can separately compute measures of a worker's base wage and a broader wage measure inclusive of bonuses. ${ }^{36}$

Table 14 summarizes many of our key findings and the compares them to other prominent estimates of nominal wage adjustments in the literature. We separate the table into research estimating nominal wage adjustments for job-stayers and research estimating nominal wage adjustments for the economy as a whole (inclusive of both job-stayers and job-changers). Much of the literature focuses on measures of earnings per hour that incorporates both base wage compensation, bonuses, and other earnings such as overtime premiums.

Using the panel component of the CPS, Daly and Hobijn (2014) report that roughly 85 percent of wages of job-stayers (measured by earnings per hour) change annually during a sample period that overlaps with ours. ${ }^{37}$ As noted above, we find that only about two-thirds

\footnotetext{
${ }^{36}$ There is a long literature, surveyed by Bewley (2004) and Howitt (2002), examining the root causes of nominal wage rigidity. In a series of interviews with business managers responsible for compensation policy, studies have documented that the primary resistance to wage cuts arises from concerns over damaging worker morale. See, for instance, Kaufman (1984), Blinder and Choi (1990), Agell and Lundborg (1995, 1999), Campbell III and Kamlani (1997), and Bewley (1999).

${ }^{37}$ One of the earliest papers to estimate the extent of nominal wage rigidity using household level data was Kahn (1997), who used data from the Panel Study of Income Dynamics (PSID) to find that about $92 \%$
} 
of job-stayers receive an annual nominal base wage change during the 2008-2016 period. It is difficult to pinpoint why the CPS results are different than ours. First, it is well documented that there is a large amount of measurement error in both earnings and hours in household survey. ${ }^{38}$ The fact that measurement error in earnings and hours is high in household surveys can explain the higher variance of wage changes in the CPS. Second, it is unclear in household surveys whether workers are reporting only their base earnings or a broader measure of earnings inclusive of bonuses. This ambiguity makes it harder to make comparisons between household surveys and administrative data sets like

Using data from the Survey of Income and Program Participation, Barattieri et al. (2014) try to account for the measurement error in wages and hours in household data by looking for structural breaks in their individual hourly wage series. Their primary focus is on workers who are paid hourly. Given that they focus on an individual's self-reported hourly wage (reported in dollars per hour), their wage measure is similar in concept to our measure of a base wage for hourly workers. When they make their correction for measurement error, they find that the frequency of quarterly wage changes for job-stayers falls from over 50 percent to between 15 and 20 percent - depending on their adjustment procedure - during their period of study. Our quarterly frequency of base wage changes for job-stayers who are paid hourly is 20 percent which is at the upper range of their estimates. More importantly, however, they estimate a much larger fraction of downward wage adjustments. Specifically, they find that 12 percent of all quarterly wage changes for job-stayers are downward changes. That is three and half times larger than our administrative data reports. As Barattieri et al. (2014) highlight, there is substantial measurement error in household surveys with respect to measuring how nominal wages adjust. The fact that their patterns still differ relative to the ADP results is consistent with some residual measurement error remaining even after implementing their structural break procedure. ${ }^{39}$

Administrative data sets containing measures of both earnings and hours are exceedingly

of workers receive a nominal wage change during a given year.

${ }^{38}$ There is a literature documenting sizable amounts of measurement error in both income and hours in household surveys using audit studies. See, for example, Bound et al. (1989) and Bound and Krueger (1991). Bound and Krueger (1991) finds that just about forty percent of cross-sectional variance of the change in income for men in household surveys can be explained by measurement error. Bound et al. (1989) documents that the measurement error in reported hours in household surveys is even larger than the measurement error in income.

${ }^{39} \mathrm{~A}$ more recent literature has emerged using firm-level data to measure wage stickiness. Both Lebow et al. (2003) and Fallick et al. (2016) use data from the BLS's Employment Cost Index (ECI) to measure nominal wage rigidity. Unlike the household surveys or other administrative payroll data, the unit of analysis in the ECI is a job not a worker. To the extent that workers who populate a specific job are heterogeneous with respect to underlying skills, nominal wage variation could occur due to shifting sampling of different quality workers over time. Consistent with this fact, the nominal wage variation in the ECI for a given job is much larger than what we document in the payroll data for job-stayers. 
rare in the United States. As discussed above, contemporaneously, Kurmann and McEntarfer (2018) and Jardim et al. (2019) use data from the US Longitudinal Employer Household Dynamics (LEHD) and Washington State Unemployment Insurance Records to examine nominal earnings-per-hour adjustments for a sample of job-stayers who reside in Washington state over a two year period. They focus their sample on residents of Washington state because Washington requires employers to report the hours worked of their employees as part of their Unemployment Insurance program. Their findings with their high quality administrative data from Washington are consistent with our patterns for modified annual earnings (which includes both base and bonus compensation). While such measures are very informative about earnings per hour volatility, they are not well suited to decompose earnings per hour volatility into how much is coming from base wage changes versus other sources like bonuses and overtime premiums. As discussed above, understanding the movement of base wages versus bonuses may be important for disciplining models of aggregate fluctuations in the same way that understanding the distinction between reference prices and sales is important in the pricing literature.

Our paper is closest in spirit to the results in Altonji and Devereux (2000) and Fehr and Goette (2005). Altonji and Devereux (2000) uses administrative payroll data similar to ours for one large financial service company during 1996 and 1997 while Fehr and Goette (2005) uses administrative payroll data from two Swiss firms in the early 1990s. The patterns of base (administrative) wage adjustment for job-stayers these authors document within their selected companies closely match the patterns we document for the whole U.S. economy during the 2008-2016 period. They also find that bonuses allow for more downward flexibility. The fact that firm-level payroll data from an earlier period within the U.S. and Switzerland broadly matches the job-stayer results from the recent ADP data highlights the importance of using administrative payroll data to measure base wage stickiness.

Most of the above results focus on the nominal wage adjustments for job-stayers. There is a separate literature that combines aggregate time series data and medium scale DSGE models to infer the extent of aggregate nominal wage stickiness. In this literature, nominal wage adjustments are modeled as being Calvo. We highlight four such papers in Table 14. As can be seen form the table, estimates of the frequency of annual nominal wage adjustments vary markedly across papers across papers. Christiano et al. (2005) uses time series data and their model to infer that $83 \%$ of wages adjust annually. However, Christiano et al. (2014) infers that only $57 \%$ of wages adjust annually. Like with the pricing literature, estimates of nominal wage stickiness are not well disciplined in time series data. This is a point that is highlighted in Beraja et al. (2016). Using regional variation in annual earnings per hour using data from the American Community Survey (ACS), Beraja et al. (2016) find that 
nominal wages are more flexible than implied by recent time series estimates from medium scale DSGE models. They conclude that nominal wage stickiness cannot explain the reason why aggregate nominal wages did not fall more sharply during the Great Recession. The estimates of annual nominal wage adjustments using cross-region variation in Beraja et al. (2016) are similar to our aggregate annual base wage adjustment found using ADP data.

\section{Conclusion}

This paper measures nominal wage adjustments for millions of US workers during the 2008 to 2016 period using administrative payroll records. Measurement error in household surveys and missing hours in administrative earnings data have prevented the development of a reliably measured set of moments for the distribution of worker compensation adjustment. Exploiting payroll data from the largest payroll processing company in the US gives measures of workers' per-period contract rate as well as other forms of worker compensation without error. We define a worker's base wage as either being their per period contracted salary (for salaried workers) or their hourly contracted wage (for hourly workers). For the median worker, about 97 percent of their annual gross earnings (excluding fringe benefits) accrues from their base wages suggesting that base wages are by far the most important component of compensation for most workers. However, there exists a subset of workers who only receive about 80 percent of their compensation from base wages. For these workers other forms of compensation, like bonuses, are also important.

Some of our key findings are qualitatively similar to the existing literature. However, the magnitudes are often quantitatively quite different. In particular, we estimate that over our entire sample period, roughly one-third of workers receive no nominal base wage change over a 12 month period and only about 2 percent of workers receive a nominal base wage cut. The extreme apparent downward nominal wage rigidity for base wages is the first main take-away of the paper.

However, despite the fact that base contract wages are essentially never cut, worker wages do adjust downwards in the aggregate owing to other margins of adjustment. Bonus payments to workers vary greatly from year to year: roughly 16 percent of workers receive an annual decline in wages on-the-job, inclusive of bonus payments. However, bonuses provide little flexibility for workers at the bottom of the wage distribution because such workers rarely receive bonuses. Highlighting these additional margins of flexibility is an additional contribution of the paper. The differential adjustment patterns of various compensation forms urges careful theoretical consideration over the correct notion of "wage rigidity." The evidence presented in this paper suggests that workers' contracts, which specify base wages 


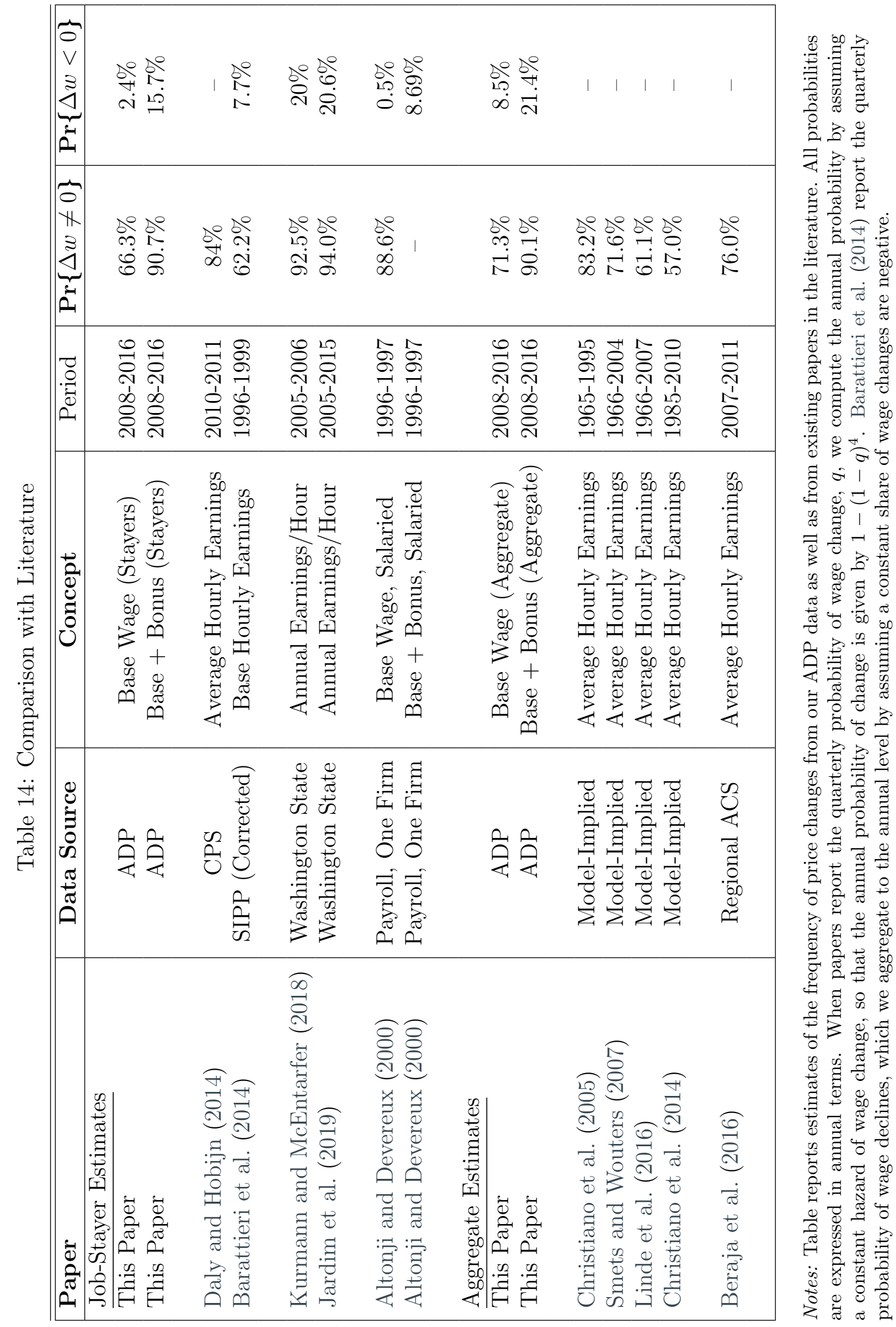


and a bonus schedule, may be quite rigid, particularly on the downside. However, workers' realized compensation, which includes both base pay and bonuses, may be quite flexible, as stipulated by the (explicit or implicit) contract governing their employment relationship.

Another key result of our paper is that job-changers provide an additional form of wage flexibility for the aggregate economy. Approximately 40 percent of job-changers receive a nominal base wage decline within a year. Since wages in the aggregate are a combination of the wage movements of both job-stayers and job-changers, this margin is key to determining the role that nominal wage rigidity plays in explaining aggregate wage dynamics. The combination of bonus adjustments and job-changers imply that aggregate wages are more flexible than one would infer by looking only at base contract wages of job-stayers, as much of the literature has done.

Finally, we show that worker wage adjustments are state dependent. During some months of the Great Recession, 6 percent of job-stayers on average received a base wage cut. In some industries, upwards of 10 percent of job-stayers received a base wage cut. Worker wage growth is procyclical for job-stayers. The state dependence is also shown using firm-level employment growth variation with shrinking firms being much more likely to cut nominal wages relative to growing firms, particularly during the Great Recession. Moreover, during the Great Recession, growing firms were much more likely to cut the wages of their workers than similarly growing firms during the 2012-2016 recovery. We also documented that new hire wages seem to adjust similarly as incumbent worker wages at business cycle frequencies.

The goal of the paper is to provide a set of moments that can be used to both guide and discipline models of nominal wage adjustments. The nominal wage flexibility we estimate using detailed micro data is broadly consistent with the flexibility of wages estimated in Beraja et al. (2016) using cross-region variation. Beraja et al. (2016) show that wage adjustments of the sort we identified cannot explain why aggregate wage growth remained robust during the Great Recession. However, one drawback of the model put forth by Beraja et al. (2016) is that it has no role for the type of asymmetry in nominal wage adjustments that this paper highlights. Going forward, research should explore whether the asymmetry in nominal wage adjustments substantially alters the conclusions of models with wage rigidity. Our state dependence results also suggest reason to move away from Calvo models of wage adjustment, which are prevalent in many modern New Keynesian models, and instead develop menu cost models of wage adjustment. Finally, our results highlight that different types of compensation have different degrees of flexibility and the compensation composition differs markedly across workers. Understanding what drives such differences and whether or not such differences have macro implications is a potentially fruitful area for future work.

We end by acknowledging that our results are useful for disciplining static models of wage 
adjustments. However, workers and firms may make dynamic contracts. In such models, a firm may hire a worker based on the present value of payments made to the worker over the expected duration of the employment relationship. Both Kudlyak (2014) and Basu and House (2016) highlight the importance of the flexibility of the user cost of hiring a worker. However, we believe that going forward the ADP data could be useful in measuring such concepts, especially as the length of the panel grows. 


\section{References}

Agell, Jonas and Per Lundborg, "Theories of Pay and Unemployment: Survey Evidence from Swedish Manufacturing Firms," The Scandinavian Journal of Economics, 1995, 97 (2), 295-307.

_ and _ , "Survey evidence on wage rigidity and unemployment: Sweden in the 1990s," 1999.

Altonji, Joseph G. and Paul J. Devereux, "The Extent and Consequences of Downward Nominal Wage Rigidity," in Solomon Polachek and Konstantinos Tatsiramos, eds., Research in Labor Economics Volume 19, Emerald Group Publishing Limited, 2000, pp. 383431.

Barattieri, Alessandro, Susanto Basu, and Peter Gottschalk, "Some Evidence on the Importance of Sticky Wages," American Economic Journal: Macroeconomics, 2014, 6 (1), 70-101.

Basu, Sustanto and Chris House, "Allocative and Remitted Wages: New Facts and Challenges for Keynesian Models," in John B. Taylor and Harald Uhlig, eds., John B. Taylor and Harald Uhlig, eds., Vol. 2 of Handbook of Macroeconomics, Elsevier, 2016, pp. $297-354$.

Beraja, Martin, Erik Hurst, and Juan Ospina, "The Aggregate Implications of Regional Business Cycles," Working Paper 21956, National Bureau of Economic Research February 2016.

Bewley, Truman, "Fairness, Reciprocity, and Wage Rigidity," 2004.

Bewley, Truman F., Why Wages Don't Fall During a Recession, Cambridge, MA: Harvard University Press, 1999.

Bils, Mark and Pete Klenow, "Some Evidence on the Importance of Sticky Prices," Journal of Political Economy, 2004, 112 (5), 947-985.

Bils, Mark J, "Real Wages over the Business Cycle: Evidence from Panel Data," Journal of Political Economy, 1985, 93 (41), 666-689.

Blinder, Alan S. and Don H. Choi, "A Shred of Evidence on Theories of Wage Stickiness Author," The Quarterly Journal of Economics, 1990, 105 (4), 1003-1015.

Bound, John and Alan B. Krueger, "The Extent of Measurement Error in Longitudinal Earnings Data: Do Two Wrongs Make a Right?," Journal of Labor Economics, 1991, 9 (1), 1-24.

_, Charles Brown, Greg J. Duncan, and Willard L. Rodgers, "Measurement Error In Cross-Sectional and Longitudinal Labor Market Surveys: Results From Two Validation Studies," NBER Working Papers 2884, National Bureau of Economic Research, Inc March 1989. 
Brown, Charles and James Medoff, "The Employer Size Wage Effect," 1989.

Cahuc, Pierre, Fabien Postel-Vinay, and Jean-Marc Robin, "Wage Bargaining with On-the-Job Search: Theory and Evidence Author," Econometrica, 2006, 74 (2), 323-364.

Calvo, Guillermo, "Staggered Prices in a Utility-Maximizing Framework," Journal of Monetary Economics, 1983, 12, 383-398.

Campbell III, Carl M. and Kunal S. Kamlani, "The Reasons for Wage Rigidity: Evidence from a Survey of Firms," The Quarterly Journal of Economics, 1997, 112 (3), 759-789.

Card, David and Dean Hyslop, "Does Inflation "Grease the Wheels of the Labor Market?"," 1997.

Christiano, Lawrence J, Martin Eichenbaum, and Charles L Evans, "Nominal Rigidities and the Dynamic Effects of a Shock to Monetary Policy," Journal of Political Economy, 2005, 113 (1), 1-45.

_, Martin S Eichenbaum, and Mathias Trabandt, "Unemployment and Business Cycles," 2015.

Christiano, Lawrence J., Roberto Motto, and Massimo Rostagno, "Risk Shocks," American Economic Review, January 2014, 104 (1), 27-65.

Daly, Mary C and Bart Hobijn, "Downward Nominal Wage Rigidities Bend the Phillips Curve," 2014.

Eichenbaum, Martin, Nir Jaimovich, and Sergio Rebelo, "Reference Prices, Costs, and Nominal Rigidities," American Economic Review, February 2011, 101 (1), 234-62.

Elsby, Michael W, Donggyun Shin, and Gary Solon, "Wage Adjustment in the Great Recession," 2013.

Fallick, Bruce C, Michael Lettau, and William L Wascher, "Downward Nominal Wage Rigidity in the United States During and After the Great Recession," 2016.

Fehr, Ernst and Lorenz Goette, "Robustness and real consequences of nominal wage rigidity," Journal of Monetary Economics, 2005, 52 (4), 779 - 804.

Gertler, Mark, Christopher Huckfeldt, and Antonella Trigari, "Unemployment Fluctuations, Match Quality, and the Wage Cyclicality of New Hires," 2016.

Guvenen, Fatih, Fatih Karahan, Serdar Ozkan, and Jae Song, "What Do Data on Millions of U.S. Workers Reveal about Life-Cycle Earnings Dynamics?," 2015.

_ , Serdar Ozkan, and Jae Song, "The Nature of Countercyclical Income Risk," Journal of Political Economy, 2014, 122 (3), 621-660. 
Haefke, Christian, Marcus Sonntag, and Thijs van Rens, "Wage Rigidity and Job Creation," Journal of Monetary Economics, 2013, 60, 887-899.

Hazell, Jonathan and Bledi Taska, "Posted Wage Rigidity," MIT Working Paper, 2018.

Howitt, Peter, "Looking Inside the Labor Market: A Review Article," Journal of Economic Literature, 2002, 40 (March), 125-138.

Hyatt, Henry R. and James R. Spletzer, "The Shifting Job Tenure Distribution," 2016.

Jardim, Ekaterina S., Gary Solon, and Jacob L. Vigdor, "How Prevalent Is Downward Rigidity in Nominal Wages? Evidence from Payroll Records in Washington State," 2019.

Kahn, Shulamit, "Evidence of Nominal Wage Stickiness from Microdata," The American Economic Review, 1997, 87 (5), 993-1008.

Kaplan, Greg and Giovanni L. Violante, "A Model of the Consumption Response to Fiscal Stimulus Payments," Econometrica, 2014, 82 (4), 1199-1239.

Kaufman, Roger T., British Journal of Industrial Relations, 1984, 22, 101 - 112.

Kehoe, Patrick J. and Virgiliu Midrigan, "Temporary Price Changes and the Real Effects of Monetary Policy," 2008.

Klenow, Peter J. and Oleksiy Kryvtsov, "State-Dependent or Time-Dependent Pricing: Does it Matter for Recent U.S. Inflation?," The Quarterly Journal of Economics, 2008, $123(3), 863-904$.

Kudlyak, Marianna, "The cyclicality of the user cost of labor," Journal of Monetary Economics, 2014, 68, 53-67.

Kurmann, Andre and Erika McEntarfer, "Downward Wage Rigidity in the United States: New Evidence from Administrative Data," 2018.

Lebow, David E, Raven E Saks, and Beth Anne Wilson, "Downward Nominal Wage Rigidity: Evidence from the Employment Cost Index," Advances in Macroeconomics, 2003, $3(1)$.

Linde, Jesper, Frank Smets, and Rafael Wouters, "Challenges for Macro Models Used at Central Banks," Working Paper, Sveriges Riksbank Research Paper Series 2016.

Martins, Pedro S., Gary Solon, and Jonathan P. Thomas, "Measuring What Employers Do about Entry Wages over the Business Cycle: A New Approach," American Economic Journal: Macroeconomics, 2012, 4 (4), 36-55.

Menzio, Guido and Shouyong Shi, "Efficient Search on the Job and the Business Cycle," Journal of Political Economy, 2011, 119 (3), 468-510.

Midrigan, Virgiliu, "Menu Costs, Multiproduct Firms, and Aggregate Fluctuations," Econometrica, 2011, 79 (4), 1139-1180. 
Nakamura, Emi and Jón Steinsson, "Five facts about prices: a reevaluation of menu cost models," The Quarterly Journal of Economics, 2008, 123 (4), 1415-1464.

Pissarides, Christopher A, "The Unemployment Volatility Puzzle: Is Wage Stickiness the Answer?," Econometrica, 2009, 77 (5), 1339-1369.

Postel-Vinay, Fabien and Jean-Marc Robin, "Equilibrium Wage Dispersion with Worker and Employer Heterogeneity," Econometrica, 2002, 70 (6), 2295-2350.

Schmitt-Grohé, Stephanie and Martin Uribe, "The Making of a Great Contraction with a Liquidity Trap and a Jobless Recovery," 2012.

Schoefer, Benjamin, "The Financial Channel of Wage Rigidity," Working Paper, 2016.

Shin, Donggyun and Gary Solon, "New Evidence on Real Wage Cyclicality Within Employer-Employee Matches," Scottish Journal of Political Economy, 2007, 54 (5), 648660 .

Smets, Frank and Rafael Wouters, "Shocks and Frictions in US Business Cycles: A Bayesian DSGE Approach," The American Economic Review, 2007, 97 (3), 586-606.

Solon, Gary, Robert Barsky, and Jonathan Parker, "Measuring the Cyclicality of Real Wages: How Important is Composition Bias," Quarterly Journal of Economics, 1994, 109 (1), 1-25.

_, Warren Whatley, and Ann Huff Stevens, "Wage Changes and Intrafirm Job Mobility over the Business Cycle: Two Case Studies," ILR Review, 1997, 50 (3), 402-415.

Taylor, John B, "Staggered Wage Setting in a Macro Model," American Economic Review, 1979, 69 (2), 108-113.

_ , "Aggregate Dynamics and Staggered Contracts," Journal of Political Economy, 1980, 88 (1), 1-23. 


\section{Online Appendix: \\ "Aggregate Nominal Wage Adjustments: New Evidence from Administrative Payroll Data" (Not for Publication)}

\section{Appendix A Benchmarking ADP Data}

In this section, we benchmark the ADP data to various other data sources.

\section{Appendix A.1 Demographics and Worker Tenure}

Table A1 shows some additional summary statistics for our ADP employee sample pooling across all years (column 1) and for selected individual years (columns 2-4). In particular, we show statistics for 2008 (our first year of data), 2012 (a middle year of data), and 2016 (our last year of data). The age, sex, and tenure distributions in our ADP sample matches well the age, sex, and tenure distributions of workers in nationally representative surveys such as the Current Population Survey (CPS). Additionally, according to the BLS, median tenure for workers over the age of 25 was about 65 months in 2012 and 2014 and was about 60 months in 2016. About one-fifth of our sample is paid weekly while three-quarters is paid bi-weekly. Less than five percent are paid monthly.

Given that ADP is growing over time, so too is our sample. Of our 1 million workers in our employee sample, only 220,000 are in our sample in 2008 while 377,000 are in our sample in 2016. Despite the growing sample size over time as ADP expands its business, the demographic composition of workers is essentially constant over time. One distinction is that average tenure is falling over time. Given that the Great Recession occurred early in our sample, it is not surprising that average tenure fell as many workers became displaced during the recession and eventually re-entered employment as the recovery took hold post2012. Indeed, the roughly 6-month decline in worker tenure between 2012 and 2016 is also found in BLS data. However, worker tenure in the ADP data is higher in 2008 than similar 2008 numbers reported by the BLS.

\section{Appendix A.2 Fraction Paid Hourly}

For our sample, 66 percent are paid hourly with the remaining 34 percent being classified as salaried workers. According to data from the CPS monthly supplements, only 57 percent of 